\author{
UNIVERSIDADE DE SÃO PAULO \\ FACULDADE DE CIÊNCIAS FARMACÊUTICAS DE RIBEIRÃO PRETO
}

Produção distinta da histopatologia e modulação de citocinas durante a infecção oral e intraperitoneal com cepa $Y$ de Trypanosoma cruzi

Christian Collins Kuehn

RIBEIRÃO PRETO 


\author{
UNIVERSIDADE DE SÃO PAULO \\ FACULDADE DE CIÊNCIAS FARMACÊUTICAS DE RIBEIRÃO PRETO
}

\title{
Produção distinta da histopatologia e modulação de citocinas durante a infecção oral e intraperitoneal com cepa $Y$ de Trypanosoma cruzi
}

\author{
Tese de Doutorado apresentada ao Programa de Pós- \\ Graduação em Biociências Aplicadas à Farmácia para \\ obtenção do Título de Doutor em Ciências. \\ Área de Concentração: Biociências Aplicadas à Farmácia. \\ Orientado: Christian Collins Kuehn \\ Orientador: Prof. Dr. José Clóvis do Prado Junior \\ Co-orientadora: Profa. Dra. Maria Dolores Bargues \\ Castelló
}

Versão corrigida da Tese de Doutorado apresentada ao Programa de Pós-Graduação Biociências Aplicada a Farmácia em 01/11/2013. A versão original encontra-se disponível na Faculdade de Ciências Farmacêuticas de Ribeirão Preto/USP. 


\section{FICHA CATALOGRÁFICA}

AUTORIZO A REPRODUÇÃO E DIVULGAÇÃO TOTAL OU PARCIAL DESTE TRABALHO, POR QUALQỦER MEIO CONVENCIONAL OU ELETRÔNICO, PARA FINS DE ESTUDO E PESQUISA, DESDE QUE CITADA A FONTE.

Kuehn, Christian Collins

Produção distinta da histopatologia e modulação de citocinas durante a infecção oral e intraperitoneal com cepa $Y$ de Trypanosoma cruzi. Ribeirão Preto 2013.

46p.: II.; $30 \mathrm{~cm}$

Tese de Doutorado, apresentada à Faculdade de Ciências Farmacêuticas de Ribeirão Preto/USP - Área de concentração: Biociências Aplicadas à Farmácia.

Orientador: Prado Junior, José Clóvis

1. Tryapanosoma cruzi. 2. Infecção oral. 3. Infecção intraperitoneal. 


\section{FOLHA DE APROVAÇÃO}

Christian Collins Kuehn

Produção distinta da histopatologia e modulação de citocinas durante a infecção oral e intraperitoneal com cepa $Y$ de Trypanosoma cruzi.

Tese de Doutorado apresentada ao Programa de Pós-Graduação em Biociências Aplicadas à Farmácia para obtenção do Título de Doutor em Ciências

Área de Concentração: Biociências Aplicadas à Farmácia.

Orientador: Prof. Dr. José Clóvis do Prado Junior

Aprovado em:

\section{Banca examinadora}

Prof. Dr.

Instituição:

Assinatura:

Prof. Dr.

Instituição:

Assinatura:

Prof. Dr.

Instituição:

Assinatura:

Prof. Dr.

Instituição:

Assinatura:

Prof. Dr.

Instituição:

Assinatura: 
Dedico este trabalho à meus pais Sebastião Pache Kuehn e Carmem Collins Kuehn bem como minha irmã Kelly Cristina Collins Kuehn, que estiveram ao meu lado em todos os momentos apesar da enorme distância que nos separa. Agradeço por sonharem comigo os meus sonhos e por me concederem a essência do amor e os ensinamentos que foram necessários para que eu os realizasse na trajetória de minha vida. 


\section{AGRADECIMENTOS}

Ao se refletir sobre a trajetória de uma vida relacionada aos estudos e as pesquisas, meus pensamentos se voltam ao agradecimento de nosso Deus, que por sua benevolência nos concede a sabedoria e humanização para lidarmos com nossos desafios, tanto no âmbito de uma dualidade espiritual como física, para concretizarmos os nossos objetivos e sonhos.

À minha família, iniciando-se pelo meu querido pai, pelo seu amor incondicional e por seus esforços imensos para que eu sempre conquiste os meus sonhos, não importando as adversidades.

À minha amada mãe, que me encoraja, me anima e me mostra que a vida é para aqueles que têm coragem, como ela um dia teve e tem. E que faz disso um exemplo a ser seguido.

A minha irmã, a qual me serve de inspiração e exemplo para as minhas vitórias e futuras conquistas no âmbito profissional e familiar, devido ao fato de ser a primogênita e dotada de extrema amorosidade.

Ao meu orientador, Prof. Dr. José Clóvis do Prado Junior, por ter aberto uma porta intitulada "oportunidade", aos meus primeiros passos a caminho da docência e pesquisa, e ensinar-me que é através dos meus feitos à porta se manterá aberta por toda uma vida.

E a todos os professores, profissionais técnicos e pós - graduandos do laboratório de Parasitologia da Faculdade de Ciências Farmacêuticas de Ribeirão Preto - USP, pela contribuição disponibilizada à minha formação acadêmica, científica e humana no decorrer de todos estes anos. 
"Tudo é ousado para quem a nada se atreve" Shigueo Watanabe 


\section{RESUMO}

KUEHN, C. C. Produção distinta da histopatologia e modulação de citocinas durante a infecção oral e intraperitoneal com cepa $Y$ de Trypanosoma cruzi. 2013. 46f. Tese (Doutorado). Faculdade de Ciências Farmacêuticas de Ribeirão Preto - Universidade de São Paulo, Ribeirão Preto, 2013.

Os surtos de doença de Chagas aguda estão relacionados ao consumo de comidas e bebidas contaminadas por fezes de triatomíneos contendo tripomastigotas de $T$. cruzi, tornando assim a infecção oral uma importante via de transmissão. Ambas as infecções vetoriais e orais desencadeiam importantes manifestações cardíacas nos hospedeiros e que estão relacionadas a uma desregulada resposta imune. $O$ objetivo deste estudo foi avaliar a parasitemia sanguínea durante a fase aguda da infecção, a produção de macrófagos peritoneais, alterações nas sub-populações de linfócitos CD4+/CD8+, citocinas Th1 e Th2, concentração de nitrito e a histopatologia cardíaca. Um grupo de ratos Wistar foi intraperitonealmente infectados com $1 \times 10^{5}$ com cepa $Y$ de tripomastigotas sanguíneos de $T$. cruzi e outro grupo de ratos Wistar foi infectado oralmente com $8 \times 10^{5}$ de tripomastigotas metacíclicos da mesma cepa. A infecção intraperitoneal desencadeou um aumento estatístico no aumento do número de parasitas, macrófagos peritoneais, proliferação de células T CD4+ e CD8+, aumento na concentração de NO, IL-12 e elevado foco inflamatório cardíaco quando comparado à infecção oral. Entretanto nossos resultados demonstraram que a infecção oral pode levar a uma doença sistêmica e que as diferentes vias de inoculação promovem respostas imunes distintas.

Palavra-chave: Trypanosoma cruzi, infecção oral e infecção intraperitoneal. 


\begin{abstract}
KUEHN, C. C. Distinctive histopathology and modulation of cytokine production during oral and intraperitoneal Trypanosoma cruzi $\mathbf{Y}$ strain infection. 2013. 46f. Thesis (Doctoral). Faculdade de Ciências Farmacêuticas de Ribeirão Preto - Universidade de São Paulo, Ribeirão Preto, 2013.
\end{abstract}

Acute Chagas disease outbreaks are related to the consumption of food or drink contaminated by triatomine feces containing trypomastigotes of $T$. cruzi, thus making oral infection an important route of transmission. Both vectorial and oral infections trigger important cardiac manifestations in the host that are related to a dysregulated immune response. The aims of this work were to evaluate the number of blood trypomastigotes during the acute phase of infection, peritoneal macrophages, possible alterations of lymphocyte CD4+/CD8+ sub-populations, Th1 and Th2 cytokines, nitrite concentrations and cardiac histopathology. One group of male Wistar rats was intraperitoneally infected with $1 \times 10^{5}$ blood trypomastigotes of the $T$. cruzi $Y$ strain, and another group of Wistar rats was orally infected with $8 \times 10^{5}$ metacyclic trypomastigotes of the same strain. The intraperitoneal infection triggered statistically enhanced parasite numbers, peritoneal macrophage numbers, proliferation of CD4+ and CD8+ T cells, increased concentrations of NO and IL-12 and elevated cardiac inflammatory foci when compared to the oral infection. Therefore, our results demonstrate that oral infection can lead to systemic disease and that the different inoculation routes promoted distinct immune responses.

Keywords: Trypanosoma cruzi, oral infection and intraperitoneal infection. 


\section{RESUMEN}

KUEHN, C. C. Producción distinta de la histopatología y modulación de citoquinas durante la infección intraperitoneal $y$ oral con la cepa $Y$ del Trypanosoma cruzi. 2013. 46f. Tesis (Doctorado). Faculdade de Ciências Farmacêuticas de Ribeirão Preto - Universidade de São Paulo, Ribeirão Preto, 2013.

Los brotes de enfermedad de Chagas agudos están relacionados a la ingestión de comidas y bebidas infectadas por heces de triatominos con tripomastigotas de $T$. cruzi lo que torna la infección oral una importante vía de transmisión. Ambas las infecciones vectoriales y orales desencadenan importantes manifestaciones cardiacas en los hospederos y que están relacionadas a una desreglada respuesta inmune. El objetivo de este estudio fue evaluar la parasitemía sanguínea durante la fase aguda de la infección, producción de macrófagos peritoneales, las posibles alteraciones en las subpoblaciones de linfocitos CD4+/CD8+, citoquinas Th1 y Th2, concentración de nitrito y la histopatología cardiaca. Un grupo de ratas Wistar fue intraperitonealmente infectado con $1 \times 10^{5}$ de la cepa $Y$ de tripomastigotes sanguíneos de T.cruzi y otro grupo de ratas Wistar fue infectado oralmente con $8 \times 10^{5}$ de tripomastigotes metacíclicos de la misma cepa. La infección intraperitoneal desencadenó un aumento estadístico del número de parásitos, macrófagos peritoneales, proliferación de células T CD4+ y CD8+, además del aumento en la concentración de NO, IL-12 y elevado foco inflamatorio cardiaco, cuando comparado a la infección oral. Entretanto nuestros resultados demostraron que la infección oral puede llevar a una enfermedad sistémica y que las diferentes vías de inoculación promueven respuestas inmunes distintas.

Palabras llave: Trypanosoma cruzi; infección oral; infección intraperitoneal. 


\section{LISTA DE FIGURAS}

Figura 1: A. Via de infecção vetorial e oral por tripomastigotas metacíclicos, B. Ativação das GP82, GP30 e GP90 no contato parasito/células do hospedeiro (via vetorial macrófagos / via oral - mucina e tecido estomacal) C. Ativação das vias de sinalização de Ca2+ por tripomastigotas metacíclicos de T. cruzi durante a invasão das células alvo do hospedeiro por ambas as vias de infecção. (YOSHIDA et al, 2006) .....

Figura 2: A. Primeira fase de infecção vetorial e oral com formas tripomastigotas metacíclicas. B. Tripomastigotas sanguíneos oriundos de formas amastigotas da infecção primária ( $1^{\circ}$ fase de infecção). C. Interação de tripomastigotas sanguíneos de $T$. cruzi com a matriz extracelular de células fagocíticas e teciduais usando moléculas tais como GP85 e penectrina, que tem afinidade por laminina, fibronectina, colágeno e heparina (YOSHIDA et al, 2006).....

Figura 3: Curva de parasitemia em ratos Wistar machos infectados com $1 \times 10^{5}$ formas tripomastigotas metacíclicas da cepa $Y$ por via intraperitoneal (I.P) e $8 \times 10^{5}$ formas tripomastigotas metacíclicas da cepa $Y$ de T. cruzi, para a infecção oral (I.O). As análises estatísticas foram feitas no pico de parasitemia $14^{\circ}$ dia para I.P e $21^{\circ}$ dia para I.O. Para todos os grupos utilizamos $n=5$. ${ }^{*} P<0,05$

Figura 4: Quantificação de macrófagos do lavado peritoneal de ratos Wistar machos infectados com $1 \times 10^{5}$ formas tripomastigotas metacíclicas da cepa $Y$ de $T$. cruzi por via intraperitoneal (I.P) realizadas no $14^{\circ}$ dia, e com $8 \times 10^{5}$ formas tripomastigotas metacíclicas da mesma cepa para a infecção oral (I.O) no $21^{\circ}$ dia. Para todos os grupos utilizamos $n=5$. * $P<0,05$

Figura 5: Análise fenotípica da população de linfócitos $\mathrm{T} C D 4^{+}$e $C D 8^{+}$do baço de ratos Wistar machos infectados com $1 \times 10^{5}$ formas tripomastigotas metacíclicas da cepa $Y$ de $T$. cruzi por via intraperitoneal (I.P) realizadas no $14^{\circ}$ dia, e com $8 \times 10^{5}$ formas tripomastigotas metacíclicas da mesma cepa para a infecção oral (I.O) no $21^{\circ}$ dia. Para todos os grupos utilizamos $n=5$. ${ }^{*} P<0,05$.

Figura 6: Produção de IFN - y expresso em pg/ml proveniente de soro de ratos Wistar machos infectados com $1 \times 10^{5}$ formas tripomastigotas metacíclicas da cepa $Y$ de $T$. cruzi por via intraperitoneal (I.P) realizadas no $14^{\circ}$ dia, e com $8 \times 10^{5}$ formas tripomastigotas metacíclicas da mesma cepa para a infecção oral (I.O) no $21^{\circ}$ dia. Para todos os grupos utilizamos $n=5$. ${ }^{*} P<0,05$

Figura 7: Quantificação de óxido nítrico expresso em $\mu \mathrm{M}$ proveniente do soro de ratos Wistar machos infectados com $1 \times 10^{5}$ formas tripomastigotas metacíclicas da cepa $Y$ de T. cruzi por via intraperitoneal (I.P) realizadas no $14^{\circ}$ dia, e com $8 \times 10^{5}$ formas tripomastigotas metacíclicas da mesma cepa para a infecção oral (I.O) no 21을. Para todos os grupos utilizamos $n=5$. ${ }^{*} P<0,05$.

Figura 8: Produção de TNF- a expresso em pg/ml proveniente de soro de ratos Wistar machos infectados com $1 \times 10^{5}$ formas tripomastigotas metacíclicas da cepa $Y$ de $T$. cruzi por via intraperitoneal (I.P) realizadas no $14^{\circ}$ dia, e com $8 \times 10^{5}$ formas tripomastigotas metacíclicas da mesma cepa para a infecção oral (I.O) no $21^{\circ}$ dia. Para todos os grupos utilizamos $n=5$. ${ }^{*} \mathrm{P}<0,05$ 
Figura 9: Produção de IL-12 expresso em pg/ml proveniente do soro de ratos Wistar machos infectados com $1 \times 10^{5}$ formas tripomastigotas metacíclicas da cepa $Y$ de $T$. cruzi por via intraperitoneal (I.P) realizadas no $14^{\circ}$ dia, e com $8 \times 10^{5}$ formas tripomastigotas metacíclicas da mesma cepa para a infecção oral (I.O) no $21^{\circ}$ dia. Para todos os grupos utilizamos $n=5$. ${ }^{*} \mathrm{P}<0,05$

Figura 10: Produção de IL-10 expresso em pg/ml proveniente de soro de ratos Wistar machos infectados com $1 \times 10^{5}$ formas tripomastigotas metacíclicas da cepa $Y$ de $T$. cruzi por via intraperitoneal (I.P) realizadas no $14^{\circ}$ dia, e com $8 \times 10^{5}$ formas tripomastigotas metacíclicas da mesma cepa para a infecção oral (I.O) no $21^{\circ}$ dia. Para todos os grupos utilizamos $n=5$. * $P<0,05$

Figura 11: Aspectos histopatológicos observados em ratos Wistar machos infectados pela via intraperitoneal e oral com a cepa Y de T. cruzi. H \& E, 400X. A - Grupo controle sem parasitas e sem foco inflamatório. B - Infecção por via intraperitoneal. Seção do coração com miocardite intensa e foco inflamatório nas células do cardiomiócito. CInfecção por via oral. Foco inflamatório moderado e miocardite com presença de parasitas nas células cardíacas. Cada barra representa a média \pm SD de um grupo experimental constituído por cinco animais. ${ }^{*} \mathrm{P}<0,05$ / B: (I.P) - Y vs C: (I.O) - Y, dia específico de experimento 


\section{LISTA DE ABREVIATURAS E SIGLAS}

(I.O) - Infecção oral

(I.P) - Infecção intraperitoneal

MHC - Complexo principal de Histocompatibilidade

IFNY - Interferon Gama

TNFa - Fator de Necrose Tumoral Alfa

IL-12 - Interleucina 12

IL-10 - Interleucina 10

LPS - Lipopolissacarídeos

NFKB - Fator Nuclear-Kappa B

H \& E - Hematoxilina e Eosina 


\section{SUMÁRIO}

RESUMO

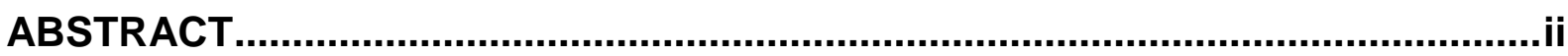

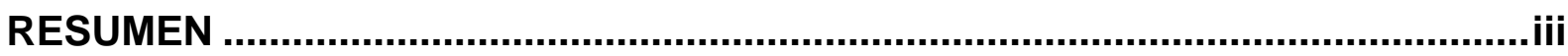

LISTA DE FIGURAS ............................................................................................

LISTA DE ABREVIATURAS E SIGLAS ...........................................................

1 INTRODUÇÃO

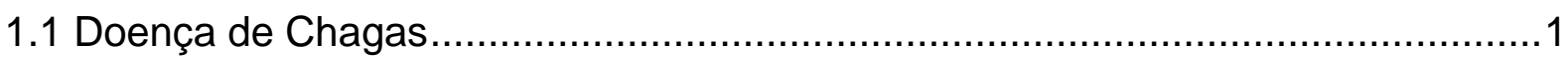

1.2 Primeira fase no mecanismo de infecção vetorial e/ou oral ............................... 4

1.3 Segunda fase do mecanismo de infecção vetorial e/ou oral ................................5

1.4 Resposta imune dirigida contra $T$. cruzi na infecção: vetorial e/ou oral................7

2 OBJETIVOS

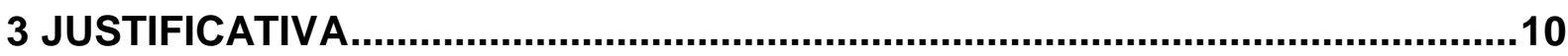

4 MATERIAIS E MÉTODOS

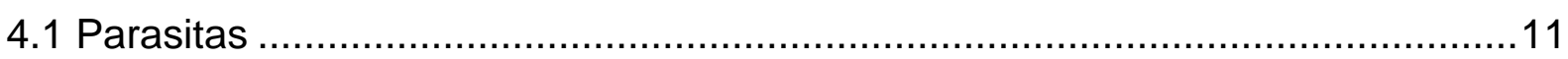

4.2 Obtenção das formas tripomastigotas metacíclicas: cepa $Y$.............................11

4.3 Viabilidade das formas tripomastigotas metacíclicas no açaí: cepa $Y$ de $T$.

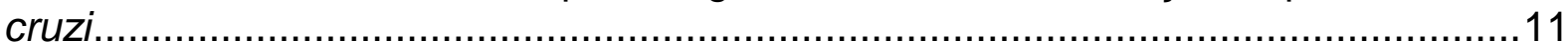

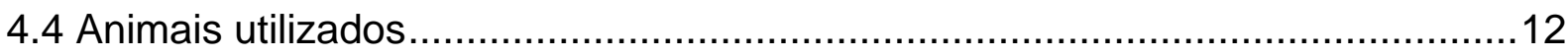

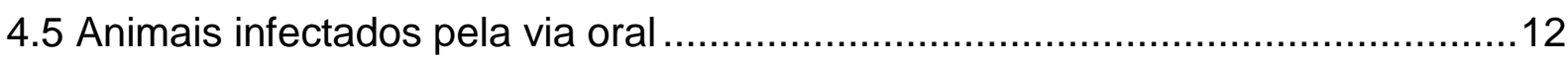

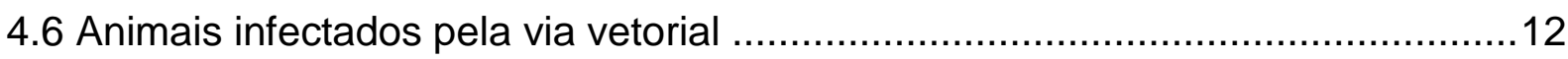

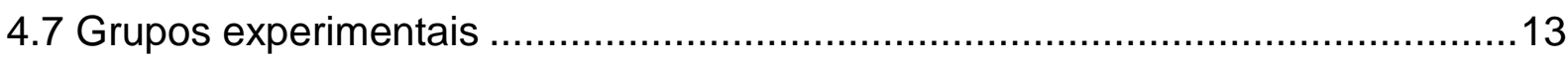

4.8 Avaliação prévia da parasitemia sobre a infecção oral .....................................13

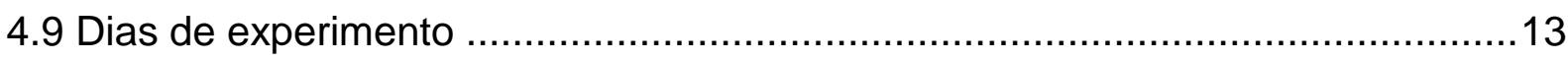

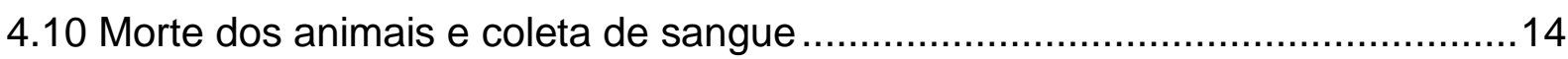

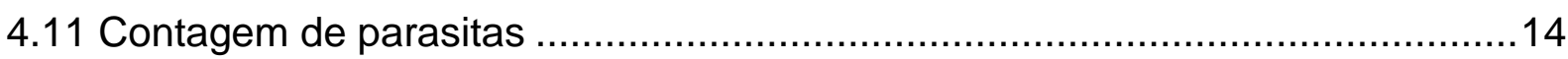

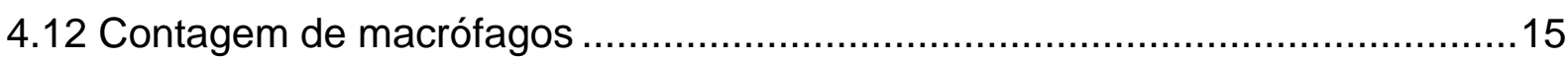

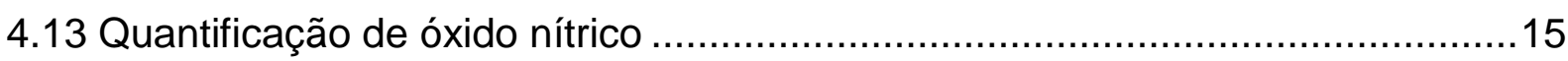

4.14 Dosagem de Citocinas Th1: TNF- $\alpha$, INF-y, IL-12 e Th2: IL10 ….....................16 
4.15 Análise fenotípica das populações celulares por citofluorimetria de fluxo .........16

4.16 Técnica histológica e intensidade do parasitismo tecidual .............................16

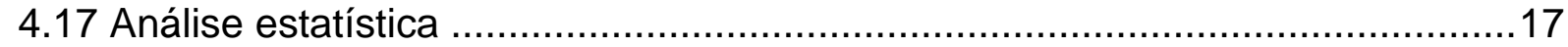

5 RESULTADOS.............................................................................................18

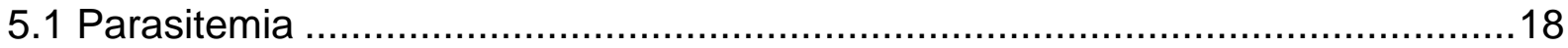

5.2 Quantificação de macrófagos ............................................................... 19

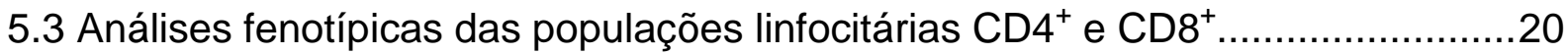

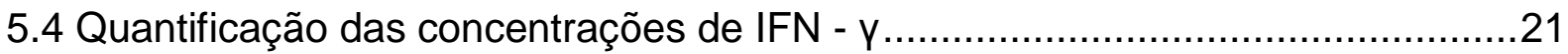

5.5 Quantificação das concentrações de Óxido Nítrico ........................................22

5.6 Quantificação das concentrações de TNF- alpha........................................23

5.7 Quantificação das concentrações de IL-12 ................................................24

5.8 Quantificação das concentrações de IL-10 .................................................25

5.9 Número de focos inflamatórios no coração .....................................................26

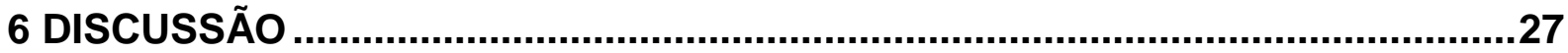

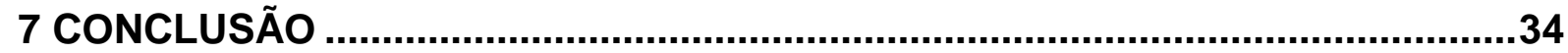

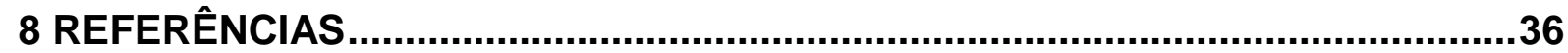




\section{INTRODUÇÃO}

\subsection{Doença de Chagas}

A doença de Chagas originou-se há milhões de anos atrás, como uma infecção enzoótica de animais silvestre e começou a ser transmitida aos seres humanos como uma antropozoonose (infecção acidental de seres humanos) quando o homem invadiu ecótopos silvestres. Embora, provas de infecção humana venham sido encontradas em múmias de até 9.000 anos de idade no Atacama, a doença de Chagas endêmica se estabeleceu como uma antropozoonose (isto é, uma doença que se transmite entre animais e seres humanos endemicamente) somente nos últimos 200-300 anos, com os triatomíneos adaptados a ambientes domésticos (COURA e DIAS, 2009).

A tripanossomiase americana é uma das patologias de mais ampla distribuição no continente americano, tornando-se uma enfermidade de grande importância na America Latina. Segundo a Organização Mundial de Saúde existem cerca 18 milhões de pessoas infectadas nas Américas, dos quais aproximadamente 6 milhões encontram-se no Brasil e 100 milhões constituem a população de risco; dos infectados cerca de 20.000 morrem a cada ano (WHO, 2002).

Os primeiros relatos da doença foram publicados no ano de 1909, pelo pesquisador Carlos Ribeiro Justiniano Chagas, médico e assistente do Instituto Oswaldo Cruz (IOC), que descreveu esta nova doença humana. Foi à primeira vez na história da medicina que um mesmo pesquisador identificava o vetor (o inseto Triatoma infestans conhecido como "barbeiro"), o agente etiológico (Trypanosoma cruzI) e as patologias causadas por esse parasito (KROPF E FERREIRA, 2000).

A doença é provocada por um protozoário flagelado da ordem Kinetoplastidae, família Trypanosomatidae denominado Trypanosoma cruzi. Apresenta como formas evolutivas os tripomastigotas metacíclicos (forma infectante para o homem), epimastigotas (formas de multiplicação no vetor e em culturas), tripomastigotas sanguícolas e amastigotas (multiplicam-se dentro das células do hospedeiro) (MORAES, 1971). 
T. cruzi promove no homem algumas manifestações clínicas distintas no período pós-infecção. Estas características estão em grande parte ligada à imunidade do hospedeiro, via de transmissão, bem como as conformações biológicas e bioquímicas de cada cepa envolvida e seu grau de virulência no hospedeiro (MILES et al., 1980; SOUZA et al., 1996). Extensivos estudos vêm caracterizando desde 1970 estas cepas de T. cruzi em biodemas e zimodemas (ANDRADE et al., 1970, 1985, 1997). Estas classificações biológicas têm sido recomendadas pela WHO (1986).

Cepas delgadas com alta capacidade de divisão como a Y (MILES et al., 1980; SOUZA et al., 1996) apresenta características especificas de patogenia no hospedeiro, devido a sua morfologia e tropismo por alguns órgãos.

Em uma escala epidemiologia crescente, avaliando a porcentagem de pessoas infectadas, podemos observar que a transmissão da doença ocorre por secreções (DEANE et al., 1979), formas congênitas, transplante de órgãos (SHIKANAI-YASSUDA et al., 1990), acidentes laboratoriais (REICHE e JANKEVICIUS, 1997), transfusão de sangue (PELLEGRINO, 1949), transmissão oral (CARLIER et al., 2002; DIAS et al., 2000) e a transmissão vetorial (CHAGAS, 1909).

A infecção vetorial ainda hoje é considerada como a principal forma de disseminação da doença e diversas espécies de triatomíneos são responsáveis por esta via de inoculação. No Brasil, os processos de combate aos triatomíneos, principalmente Triatoma infestans vêm demonstrando resultados satisfatórios em todo o Brasil (SCHOFIELD et al., 2006).

A dificuldade em eliminar a infecção vetorial é devido a grande variabilidade de triatomíneos existentes, como exemplo na região Amazônica, pois ao contrário de outras regiões brasileiras, a espécie mais predominante é Rhodinus prolixus. Este triatomíneo tem apresentado mudanças comportamentais migratórias de um ambiente silvestre para peridomiciliar, favorecendo uma elevada transmissão vetorial (SCHOFIELD, 1988).

Outra via de transmissão que vêm despontando de forma emergente $\mathrm{e}$ elevando os dados epidemiológicos é a infecção oral (CAMANDAROBA et al., 2002). Diversas pesquisas já foram realizadas com o intuito de avaliar a viabilidade de $T$. cruzi nos alimentos. Segundo AMATO NETO et al., 2000, DIAZ-UNGRÍA, 1968, LOPES E CHAPADEIRO, 2004, PINTO et aL., 1990, o parasita mostrou-se viável 
em experimentos com leite, sangue de mamíferos, carne crua, caldo-de-cana e carne de cadáver humano por pelo menos algumas horas, à temperatura ambiente, prolongando-se por dias ou semanas, em baixas temperaturas. Em caldo-de-cana, SOARES et al., (1987) lograram a viabilidade do parasita por até vinte e quatro horas, trabalhando com inóculo de fezes e triatomíneo macerado em animais como o cão e camundongo.

Casos por infecção oral vêm aumentando principalmente na região amazônica, pois o vetor contaminado com $T$. cruzi pode ser processado acidentalmente nos sucos de açaí e consequentemente ser consumido pela população local, podendo promover micro-epidemias pontuais (BARBOSA et al., 2012).

Segundo algumas pesquisas, mais de $50 \%$ dos casos agudos da doença de Chagas na região amazônica estão relacionados à infecção por via oral, através do consumo de alimentos contaminados nos anos de 1968 a 2000 (COURA et al., 2002).

Na Amazônia os três primeiros casos foram registrados em 1966, também com contaminação oral (PINTO et al., 2001). Até 2001 havia 148 casos informados, sendo 121 agudos, com 5 mortes. Somente no Pará, 71 casos foram notificados, incluindo dezessete microepidemias familiares, principalmente por ingestão de suco de açaí contaminado (VALENTE et al., 2001). Estes dados foram, confirmados por estudos epidemiológicos que vem demonstrando uma inversão da incidência de casos agudos de infecção vetorial em relação à contaminação por via oral da doença de Chagas (COURA et al., 2002).

O açaí, designação do fruto da palmeira "açaizeiro", originário da região do delta amazônico, onde cresce abundantemente neste ecossistema de várzea, representa uma importante fonte alimentar, tanto para os povos indígenas, quanto para a população ribeirinha e para alguns centros urbanos regionais, como Belém (NASCIMENTO, 1992). O estado do Pará é o maior produtor mundial dessa fruta, que segundo SANTANA E AMIM (2002) gerou, no ano de 2004, o valor de R\$ 317,83 milhões, exportou cerca de US\$ 3,87 milhões, empregou diretamente 5.650 pessoas e ocupou em algumas fases da cultura (plantio ou manejo, tratos culturais, colheita e comercialização) 150 mil pessoas, envolvendo 45 mil famílias.

Interessante notar mediante estes dados que o açaí é a fonte rentável e alimentar para uma grande quantidade da população nortista, entretanto, este fato 
pode estar ameaçado pelos altos índices de contaminação da doença de Chagas que vem se alastrando através do preparo e consumo inadequado do suco de açaí (IANNI E MADY, 2005).

Atento aos atuais fatos, alguns pesquisadores vêm direcionando suas linhas de pesquisa para uma melhor compreensão nos processos de infecção vetorial e oral na doença de Chagas, bem como analisar o perfil imunopatológico que a cepa promove nestas vias de infecção sobre o hospedeiro.

\subsection{Primeira fase no mecanismo de infecção vetorial e/ou oral}

Após a infecção das formas tripomastigotas metacíclicas provenientes da contaminação vetorial ou oral, os parasitas alcançam as primeiras barreiras naturais do hospedeiro. Em uma infecção vetorial, T. cruzi invade especialmente células do sistema fagocítico-monocitário, enquanto na infecção oral, os principais alvos são as células epiteliais do estômago.

Uma vez o hospedeiro infectado, as formas tripomastigotas metacíclicas da cepa Y apresentam glicoproteínas de membrana: GP82, GP30 e GP90, responsáveis pelo contato da primeira fase de interação célula-parasita por ambas as via de contaminação vetorial e/ou oral na doença de Chagas (BRENER, Z. 1963; SOUZA, M. M. 1996).

Os processos de infecção e intensidade de invasão celular estão diretamente regulados, pela expressão destas glicoproteínas (COVARRUBIAS et al., 2007). GP82 e GP30 presentes em cepas $Y$ favorecem a adesão celular e medeiam à entrada de formas tripomastigotas metacíclicas em células fagocíticas, bem como células epiteliais humanas, entretanto a infecção depende, sobretudo da expressão de GP82 que promove uma adesão mais efetiva (NEIRA et al. 2003; YOSHIDA, 2006). A invasão de células alvo por cepas de $T$. cruzi deficientes de GP82 está diretamente relacionada com a presença e expressão do GP30 no processo de infecção celular (CORTEZ et al., 2003).

GP90 pode ser caracterizada como uma molécula de superfície com propriedades regulatórias negativas nos processos de penetração celular (MÁLAGA e YOSHIDA, 2001), caracterizando reduzidas taxas de invasão em estudos in vitro. Em 2007, COVARRUBIAS observaram que a cepa SC provenientes de pacientes 
contaminados com caldo de cana no estado de Santa Catarina apresentava GP90 em formas tripomastigotas metacíclicas que foram degradadas pelo suco gástrico, ativando a expressão de GP82 e GP30 com consequente ativação da via de $\mathrm{Ca}^{2+}$, promovendo alta infectividade no estômago após infecção oral.

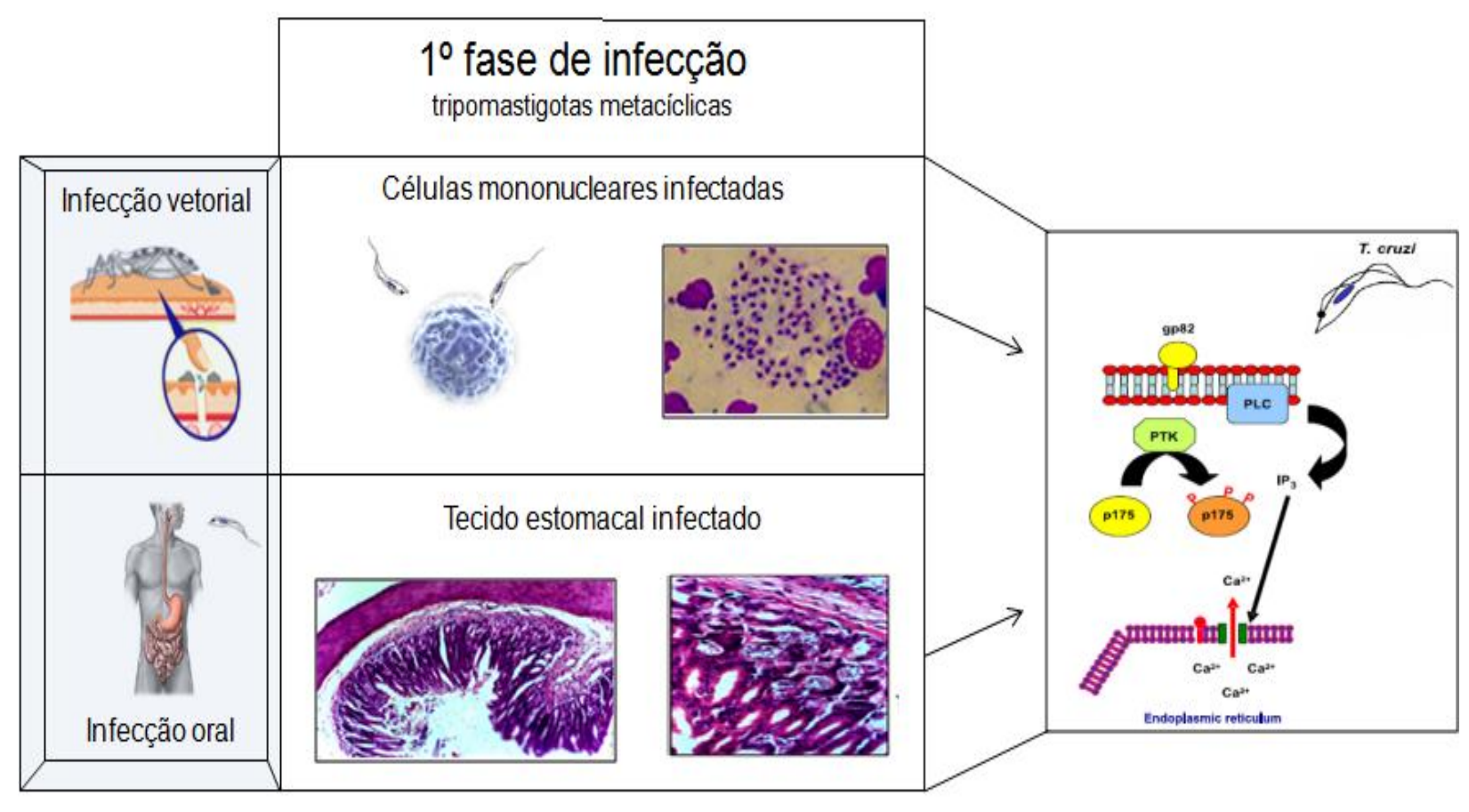

A.

B.

(Yoshida, 2008)

C.

Figura 1. A. Via de infecção vetorial e oral por tripomastigotas metacíclicos, B. Ativação das GP82, GP30 e GP90 no contato parasito/células do hospedeiro (via vetorial - macrófagos / via oral - mucina e tecido estomacal) C. Ativação das vias de sinalização de $\mathrm{Ca2+}$ por tripomastigotas metacíclicos de $T$. cruzi durante a invasão das células alvo do hospedeiro por ambas as vias de infecção (YOSHIDA et al, 2006).

\subsection{Segunda fase do mecanismo de infecção vetorial e/ou oral}

Seguindo a primeira fase de infecção vetorial ou oral, as formas tripomastigotas metacíclicas provenientes desta contaminação transformam-se em amastigotas intracelulares, e posteriormente em tripomastigotas sangüícolas que emergem das células infectadas e ganham o sistema circulatório, disseminando-se por diversos órgãos e retornando a infectar múltiplas células e tecidos do hospedeiro em uma segunda fase da infecção (COURA et al., 2002).

Formas tripomastigotas sangüíneas provenientes da segunda fase de infecção, apresentam glicoproteinas de superfície GP85/TS e proleoligopeptidase 
POP e GP80, com características semelhantes às glicoproteínas nas formas metacíclicas da primeira fase de infecção, promovendo um quadro de adesão, invasão e reconhecimento dos componentes da matriz extracelular como fibronectina, laminina, citoqueratina presentes em monócitos, neutrófilos, mucinas e produção de transialidase (GIORDIANO et al., 1994; MAGDESIAN et al. 2001; SCHENKMAN et al. 1991a; SANTANA et al., 1997, GRELLIER et al., 2001). Essas transialidases são identificadas como: cisteinas proteases, oligopeptidases e penetrina que apresentam afinidades por proteínas da matriz extracelular, ligando-se a heparina, heparan sulfato e colágeno das células (POLLEVICK et al., 1991; OUAISSI et al., 1986a).

Desta maneira, estas glicoproteinas GP82, GP30, GP90, GP85/TS e POP GP80 estão diretamente ligadas a complexos processos de adesão, sinalização e invasão de tripomastigotas metacíclicos e sangüíneos em células hospedeiras tanto em infecções vetorias como orais, considerando que formas tripomastigotas entram nas células por três mecanismos: invaginação de membrana, fagocitose, endocitose.

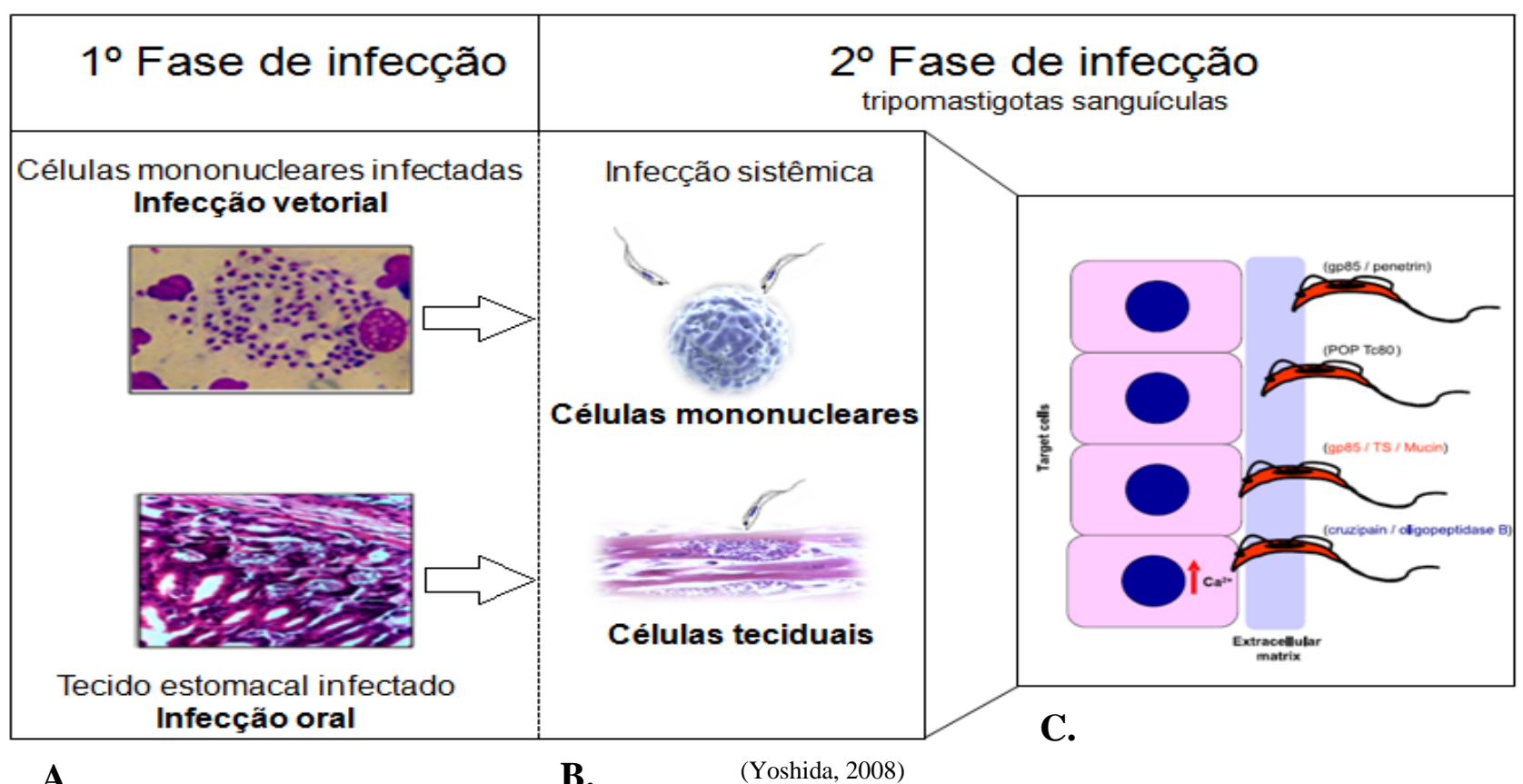

A.

B.

Yoshida, 2008

Figura 2. A. Primeira fase de infecção vetorial e oral com formas tripomastigotas metacíclicas. B. Tripomastigotas sanguíneos oriundos de formas amastigotas da infecção primária ( $1^{\circ}$ fase de infecção). C. Interação de tripomastigotas sanguíneos de $T$. cruzi com a matriz extracelular de células fagocíticas e teciduais usando moléculas tais como GP85 e penectrina, que tem afinidade por laminina, fibronectina, colágeno e heparina (YOSHIDA et al, 2006) 


\subsection{Resposta imune dirigida contra $T$. cruzi na infecção: vetorial ou oral}

A invasão de formas metacíclicas presentes, tanto na infecção vetorial como oral em células do hospedeiro definitivo, provocam uma série de interações moleculares nos macrófagos que ativam a resposta imune inata do hospedeiro, promovendo específicos sinais para as células T CD4+ e CD8+, que desempenham um papel essencial em mediar a resposta imune celular no controle de $T$. cruzi (TARLETON, 1994; REED, 1995; ALIBERTI et al., 1999). Consequentemente, a imunidade adquirida do hospedeiro infectado começa a sua defesa contra o patógeno através da produção de interleucinas. Entre estas o aumento nas concentrações de óxido nítrico (NO) é alcançado por meio da ativação da arginase expressão do gene I dentro dos macrófagos (GAZZINELLI et al., 1992; ALIBERTI et al., 1996). No entanto, a produção exacerbada de arginase I e NO durante a fase aguda da infecção está ligada à miocardite em modelos murinos susceptíveis (GARCIA et al., 1999). CAMARGO et al., (2000), trabalhando com ratos Holtzman infectados com cepas $\mathrm{ABC}, \mathrm{Y}$ e $\mathrm{Cl}$-Brener, observaram uma produção elevada de NO, consequentemente ocasionando uma miocardite aguda grave durante a fase aguda, com impacto significativo na fase crônica da doença.

Muitos trabalhos foram realizados para explicar o perfil imunopatológico do hospedeiro sobre a infecção vetorial, na infecção oral, entretanto poucos dados estão disponíveis. Ciente dos acontecimentos atuais, a nossa pesquisa teve como objetivo analisar o perfil imunológico de ratos Wistar infectados com a cepa $Y$ de $T$. cruzi após a infecção intraperitoneal e oral, utilizando como parâmetros a parasitemia sistêmica, contagem de macrófagos peritoneal, a quantificação de IL-12, IFN-y, IL-10, o óxido nítrico, populações de células T CD4 $4^{+}$e $\mathrm{CD}^{+}$por citometria de fluxo e histopatologia no tecido cardíaco.

O nosso objetivo era avaliar se o perfil imunológico do hospedeiro poderia servir como uma chave para elucidar qual tipo de infecção o mesmo foi submetido. Comparando separadamente os grupos de infecção intraperitoneal e oral infectados com a cepa $Y$. 


\section{OBJETIVOS}

$\checkmark$ Avaliar a resposta imune e a histopatologia cardíaca de ratos Wistars infectados pela via intraperitoneal e oral com a cepa $Y$ de Trypanosoma cruzi.

Analisar se o perfil imune do hospedeiro infectado é capaz de direcionar o diagnóstico pela via primaria de infecção.

Através de:

- Quantificação de parasitas sangüíneos durante a fase aguda da infecção experimental tanto por via intraperitoneal como oral;

- Contagem global de macrófagos esplênicos e peritoneais;

- Subpopulações de células T CD3+CD4+, CD3+CD8+;

- Detecção de possíveis alterações na resposta imune através da dosagem de citocinas no soro de animais infectados;

- Quantificação de Óxido Nítrico no lavado peritoneal de animais infectados;

- Avaliação histopatológica de focos inflamatórios e parasitismo tecidual em cardiomiócitos. 
$\rightarrow$ Marcadores de fenótipos celulares analisados

\begin{tabular}{|l|l|}
\hline Descrição & Marcadores celulares \\
\hline $\begin{array}{l}\text { Marcadores de célula T auxiliar e } \\
\text { Citotóxica }\end{array}$ & CD3, CD4, CD8 \\
\hline
\end{tabular}

$\rightarrow$ Citocinas analisadas

\begin{tabular}{|l|l|}
\hline Características & Citocina \\
\hline $\begin{array}{l}\text { Principal mediador da resposta imune } \\
\text { inata e indutor da resposta adaptativa }\end{array}$ & IL-12 \\
\hline $\begin{array}{l}\text { Ativação de macrófagos e células } \\
\text { Th1; Ações sobre imunidade inata e } \\
\text { adaptativa }\end{array}$ & IFN-Y \\
\hline $\begin{array}{l}\text { Principal mediador da resposta } \\
\text { inflamatória aguda }\end{array}$ & TNF- $\alpha$ \\
\hline $\begin{array}{l}\text { Regulação da resposta imune inata e } \\
\text { celular }\end{array}$ & IL-10 \\
\hline
\end{tabular}




\section{JUSTIFICATIVA}

A doença de Chagas apresenta diferentes vias de infecção para o homem. As mais frequentes são as infecções vetoriais, ocasionadas por triatomíneos que albergam T. cruzi. Estes triatomíneos estão normalmente separados por regiões, como no caso o Rhodnius prolixus presente na região Amazônica. Outra forma de infecção que vêm ganhando robustos dados epidemiológicos também na região amazônica é a infecção oral, mediante ao consumo de alimentos contaminados como o açaí in natura.

$\mathrm{Na}$ Amazônia brasileira, a doença de Chagas ainda não foi considerada endêmica, entretanto 0 número de pessoas infectadas vem aumentando consideravelmente a cada ano. O primeiro surto de transmissão oral da doença de Chagas na Amazônia foi relatado em 1968 (DEVERA et al., 2002). Durante 19682005, um total de 437 casos da doença de Chagas aguda foi relatado nesta região. Destes, 311 foram relacionados com 62 surtos, nos quais se levantou a suspeita de transmissão pelo consumo do açaí (SOUTO e ZINGALES 1993).

Apesar da grande rentabilidade e característica nutricional que o fruto apresenta para a população da região Amazônica, o açaí vem sendo frequentemente correlacionado a diversas micro-epidemias.

A apresentação clínica da doença de Chagas é muito variável, tanto pela via vetorial como oral e envolve fase aguda e crônica (SILVA et al., 1968). A resposta ao tratamento, sinais clínicos e a morbidade da doença de Chagas também estão diretamente ligadas às características biológicas, bioquímicas e genéticas das cepas de T. cruzi (VALENTE et al., 2006).

Avaliando as inúmeras possibilidades que levam um hospedeiro infectado a manifestar diferentes quadros patológicos, realizamos um detalhado estudo sobre a capacidade da infecção oral transformar-se em infecção sistêmica, bem como o perfil da síntese de citocinas e outros mediadores relacionados aos quadros patológicos nas infecções por via vetorial ou oral com a cepa $Y$ de $T$. cruzi.

Desta forma, analisando os resultados experimentais, nossa pesquisa teve como proposta inicial, obter uma melhor compreensão sobre o perfil imune, população celular e danos teciduais cardíacos promovidos por estas infecções.

Nossos resultados permitem indicar a possível via de infecção ocorrida e suas manifestações imunes e clínicas pós-infecção vetorial e oral. 


\section{MATERIAIS E MÉTODOS}

\subsection{Parasitas}

Foram utilizados tripomastigotas metacíclicos da cepa $Y$ de $T$. cruzi oriunda de triatomíneos da espécie Rhodnius prolixus por SILVA e NUSSENZWEIG (1953).

A cepa é mantida no laboratório de parasitologia da Faculdade de Ciências Farmacêuticas de Ribeirão Preto - São Paulo.

\subsection{Obtenção das formas tripomastigotas metacíclicas: cepa Y}

Cinco Rhodnius prolixus foram alimentados com sangue de camundongo infectados com cepa $Y$ de T. cruzi. Após um período de 20 a 30 dias, realizamos a compressão abdominal para a obtenção das fezes contaminadas. Sequencialmente as mesmas foram submetidas à centrifugação seriada de $100 \mathrm{~g}$ e $1000 \mathrm{~g}$ sobre uma resuspensão de meio RPMI para a separação das fezes/parasita. A quantificação de tripomastigotas metacíclicos foi obtida pela contagem em câmara de Neubauer.

\subsection{Viabilidade das formas tripomastigotas metacíclicas no açaí: cepa Y de T. cruzi}

Aproximadamente $2 \mathrm{~mL}$ de polpa de açaí in natura foram contaminadas com $8 \times 10^{5}$ de cepas $Y$ de T. cruzi oriundas de Rhodnius prolixus. Em seguida realizou-se o processo de congelamento á $-20^{\circ} \mathrm{C}$ e após 6, 12 e 24 horas o açaí foi descongelado e avaliada a mobilidade, morfologia estrutural e viabilidade das formas metacíclicas através de microscopia ótica. 


\subsection{Animais utilizados}

Utilizamos ratos machos da linhagem Wistar $(n=30)$, jovens, pesando entre 90 e 100 gramas, provenientes de uma colônia mantida da Universidade de São Paulo, campus de Ribeirão Preto. Esses animais foram ambientados no biotério da FCFRPUSP, sendo mantidos a uma temperatura ambiente de $23 \pm 2^{\circ} \mathrm{C}$, em ciclo claro e escuro 12/12 horas, com acesso livre a água e ração.

Em cada experimento, foram utilizados 5 animais por grupo, visto que uma diferença no número de amostra pode influenciar nos resultados (SOGAYAR et al., 1993). O protocolo do estudo foi aprovado pelo Comitê de Ética, local número de protocolo 09.1.989.53.5.

\subsection{Animais infectados pela via oral}

Os grupos foram infectados oralmente (I.O) através de gavagem, com $0.2 \mathrm{~mL}$ de açaí, contendo $8 \times 10^{5}$ formas tripomastigotas metacíclicas com a cepa $Y$ de $T$. cruzi resistentes ao processo de congelamento por 24 horas.

\subsection{Animais infectados através de infecção intraperitoneal ou simulação da via vetorial}

Os grupos foram infectados intraperitonealmente (I.P) com $1 \times 10^{5}$ formas tripomastigotas metacíclicas com a cepa $\mathrm{Y}$ de $T$. cruzi retiradas diretamente de triatomíneos. Este processo de inoculação intraperitoneal tem como finalidade, simular uma infecção vetorial. 


\subsection{Grupos experimentais}

Os animais foram divididos e identificados em dois grupos:

\section{- Infeccão com cepa Y}

Grupo controle:

(C) - Controle não Infectado $(n=5)$

\section{Grupos infectados:}

(I.P) - Infecção intraperitoneal com cepa $\mathrm{Y}(\mathrm{n}=5)$

(I.O) - Infecção oral com cepa $Y(n=5)$

Todos os animais foram infectados com as formas tripomastigotas metacíclicas.

Experimento realizado em duplicata.

\subsection{Avaliação prévia da parasitemia após a infecção oral}

Um grupo com cinco animais foi infectado oralmente (I.O) através de gavagem, com $0.2 \mathrm{ml}$ de açaí, contendo $1 \times 10^{5}, 5 \times 10^{5}, 7 \times 10^{5}$ e $8 \times 10^{5}$ formas tripomastigotas metacíclicas com cepas $\mathrm{Y}$ de $T$. cruzi. Em seguida foi realizada a análise da parasitemia, retirando-se o sangue da cauda dos animais todos os dias, em um período de 30 dias. Esta análise forneceu o dia especifico de pico na infecção oral e a carga parasitária correspondente ao pico de parasitemia $\left(8 \times 10^{5}\right)$.

\subsection{Dias de experimento}

Os experimentos foram realizados em dias pré-determinados baseados na curva parasitêmica e a via de infecção utilizada. 


\begin{tabular}{|c|c|}
\hline \multicolumn{1}{|c|}{ Grupos } & Pico da parasitemia \\
\hline (I.P) - Infecção intraperitoneal com cepa Y & $14^{\circ}$ dia \\
\hline (I.O) - Infecção oral com cepa Y & $21^{\circ}$ dia \\
\hline
\end{tabular}

Para cada dia de experimento no pico da infecção, foram utilizados 5 animais por grupo, para todos os grupos, visto que, uma diferença no número de amostra pode influenciar nos resultados do experimento (SOGAYAR et al., 1993). Ao final, utilizaram-se 30 animais. Os experimentos foram realizados em duplicata (independentes).

\subsection{Morte dos animais e coleta de sangue}

Os animais foram eutanasiados por decapitação após anestesia com Tribomoetanol 2,5 mg/Kg, para evitar que outras manifestações pudessem ocasionar estresse e interferir nos parâmetros analisados (CALDEIRA E FRANCI, 2000). Após a morte dos animais, foram coletados cerca de $2,0 \mathrm{~mL}$ de sangue em tubos Falcon de $15 \mathrm{~mL}$ contendo $200 \mu \mathrm{l}$ de heparina sódica (1mL: 5.000U.I.- ORGANON TEKNIKA) para posterior contagem das formas tripomastigotas sanguíneas. Para as dosagens imunológicas o sangue, foi coletado em frascos específicos sem anticoagulante com o volume de 2,0mL para a obtenção do soro.

\subsection{Contagem de parasitas}

A determinação da parasitemia sanguínea foi realizada no pico específico da cepa e via de infecção, utilizando-se o método de BRENER (1962), que consiste em colocar uma alíquota de $5 \mu \mathrm{L}$ de sangue em lâmina, cobrindo-a com lamínula de $22 \mathrm{x}$ $22 \mathrm{~mm}$. O número de parasitas é determinado contando-se em 50 campos microscópicos. O número encontrado é multiplicado por um fator, calculado para cada microscópio e objetiva, que leva em consideração o número de campos microscópicos existentes na área da lamínula. 


\subsection{Contagem de macrófagos}

Macrófagos peritoneais de animais infectados (I.P) ou (I.O) com a cepa $Y$ foram coletados imediatamente após a morte dos animais. Para tanto, injetou-se 10 ml de meio RPMI 1640 estéril (Cultlab, Campinas Brasil) na cavidade peritoneal, com posterior massagem abdominal suave por 30 segundos e, em seguida coleta do líquido peritoneal. $O$ procedimento foi também realizado nos grupos controles não infectados, mas estimulados intraperitonealmente com tioglicolato a $3 \%$, quatro dias antes ao experimento. As células foram centrifugadas por 15 minutos, sendo o "pellet" ressuspenso em meio RPMI. Utilizou-se a solução de Turk para a coloração das células macrofágicas do lavado peritoneal dos ratos, realizando-se em seguida a contagem manual em câmara de Neubauer para obtenção do número total de células sob microscopia óptica.

\subsection{Quantificação de óxido nítrico}

Os ensaios de produção de óxido nítrico foram realizados em de células do lavado peritoneal. A cavidade dos animais foi lavada com $10 \mathrm{ml}$ de RPMI, centrifugado por 10 minutos a $1500 \mathrm{rpm}$ a $4^{\circ} \mathrm{C}$ e o sobrenadante desprezado. $\mathrm{O}$ sedimento foi ressuspendido com $1 \mathrm{~mL}$ de RPMI contendo $10 \%$ de soro bovino fetal e antibiótico. Desta suspensão, retirou-se uma alíquota de $10 \mu \mathrm{L}$ que será diluída em Turk e azul de Tripan, para a contagem e viabilidade celular. Depois de contadas, as concentrações foram acertadas para $5 \times 10^{5}$ células $/ \mathrm{mL} ; 100 \mu \mathrm{L}$ desta suspensão foram distribuídas em placa de 96 poços, adicionando, $10 \mu \mathrm{g} / \mathrm{mL}$ poço de LPS. A placa foi incubada durante 24 horas a $37^{\circ} \mathrm{C}$ em estufa contendo $5 \%$ de $\mathrm{CO}_{2}$. Após este período, a placa foi submetida a centrifugação de $1500 \mathrm{rpm}$ durante 4 minutos. Recolheu-se $100 \mu \mathrm{L}$ do sobrenadante que foram transferidos para outra placa de 96 poços. Em seguida, adiciona-se igual volume de reagente de Griess, permitindo a revelação da reação por meio de leitor de microplacas, utilizando filtro de $540 \mathrm{~nm}$. A curva padrão de $200 \mu \mathrm{M}$ a $6 \mu \mathrm{M}$ foi realizada utilizando $\mathrm{NO}^{3}$ com diluição seriada na base 2 (TERENZI et al., 1995). A leitura da absorbância foi realizada em leitor de microplaca. 


\subsection{Dosagem de Citocinas Th1: TNF- $\alpha$, INF-y, IL-12 e Th2: IL10}

Os concentrações destas citocinas foram quantificados utilizando imuno ensaio (№ do Catálogo RT1000, KRCO122 e RIF00 R\&D Systems). A metodologia baseou-se nos componentes básicos para o desenvolvimento do ELISA sanduiche para a mensuração natural e recombinante das citocinas.

\subsection{Análise fenotípica das populações celulares por citofluorimetria de fluxo}

O baço foi removido cirurgicamente e os esplenócitos obtidos por maceração em peneiras de aço inox em 4mL de meio de RPMI 1640 (GibcoBR). A contagem de linfócitos TCD4+, TCD8+, foi realizada por citometria de fluxo, baseada em anticorpos monoclonais marcados com substancias fluorescentes, dirigidos contra antígenos de superfície destas células. As células foram marcadas com anticorpos monoclonais conjugados com anti-CD3-phycoerythrin (PE), anti-CD4+FITC (Fluorescein isotiocianate) e anti-CD8+PERCP (Peridin Clorofil Protein) (BDPharmingen, CA, USA). As células coradas foram armazenadas para análise em PBS contendo $0,01 \mathrm{ml}$ de azida de sódio e $1 \%$ de paraformaldeído, em tubos selados mantidos no escuro. Todos os passos foram realizados a $4 \stackrel{\circ}{ } \mathrm{C}$. Análise dessas células foi realizada utilizando uma Becton Dickinson FACScan citômetro de fluxo com o software DIVA-BD (Becton Dickinson Immunocytometry Systems, San Jose, CA, EUA).

\subsection{Técnica histológica e intensidade do parasitismo tecidual}

A presença de um infiltrado inflamatório é considerada positiva quando 30 ou mais leucócitos são detectados em cada foco inflamatório. Os corações foram coletados após a eutanásia. Os órgãos foram lavados em solução salina a $0,9 \%$, fixados em formaldeído a $10 \%$ e embebidos em parafina. Cortes histológicos de 
$6 \mu \mathrm{m}$ foram coradas com hematoxilina e eosina. Os cortes foram montados com um intervalo de $70 \mu \mathrm{m}$ para evitar a análise do mesmo foco inflamatório. Para a contagem do infiltrado inflamatório, o número total de focos foi contado em microscópio em 50 campos (ampliação 400X) por secção cardíaca. Quatro secções foram contadas para cada animal, e os dados individuais foram determinados como a média dos resultados das quatro secções. A média e desvio padrão de cinco animais são apresentados para cada grupo (CASTRO E BRENER, 1985).

\subsection{Análise estatística}

A significância estatística entre os grupos foram determinadas por análise de variância de pós-teste ANOVA complementado pelo teste de Bonferroni. Os resultados foram expressos como médias/erro padrão da média. Um valor de $\mathrm{P}<0,05$ foi considerado estatisticamente significativo. Todas as análises estatísticas foram realizadas utilizando Graph Pad Prism versão 5.0. 


\section{RESULTADOS}

\subsection{Parasitemia}

A infecção por via intraperitoneal (I.P) no 14ํำ dia pós-infecção promoveu um aumento significativo da parasitemia sanguínea quando comparado com a infecção oral (I.O) no 21ํ dia pós-infecção $(P<0,05)$ (Figura 3).
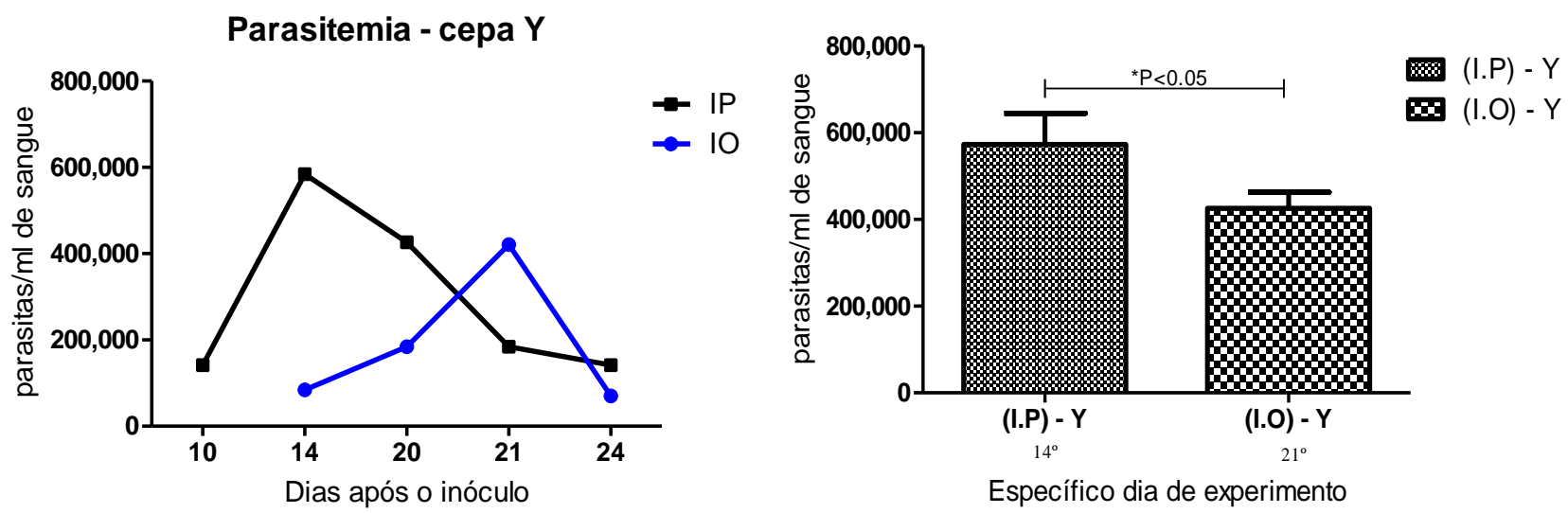

Figura 3: Curva de parasitemia em ratos Wistar machos infectados com $1 \times 10^{5}$ formas tripomastigotas metacíclicas da cepa $Y$ por via intraperitoneal (I.P) e $8 \times 10^{5}$ formas tripomastigotas metacíclicas da cepa $Y$ de $T$. cruzi, para a infecção oral (I.O). As análises estatísticas foram feitas no pico de parasitemia $14^{\circ}$ dia para I.P e $21^{\circ}$ dia para I.O. Para todos os grupos utilizamos $n=5,{ }^{*} P<0,05$. 


\subsection{Quantificação de macrófagos}

Um aumento significativo no número de macrófagos foi encontrado na infecção por via intraperitoneal (I.P) no $14^{\circ}$ dia pós-infecção, quando comparado com a infecção oral (I.O) no $21^{0}$ dia pós-infecção $(P<0,05)$. Ambas as vias de infecção exibiram números significativos de macrófagos em relação ao grupo controle não infectados $(C)(P<0,01)$ (Figura 4).

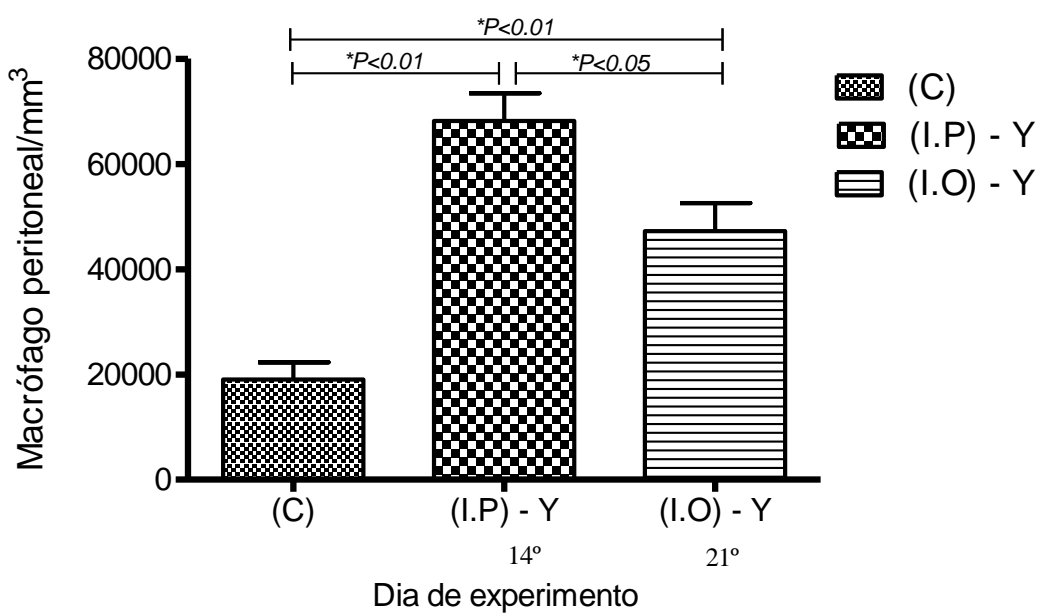

Figura 4: Quantificação de macrófagos do lavado peritoneal de ratos Wistar machos infectados com $1 \times 10^{5}$ formas tripomastigotas metacíclicas da cepa $Y$ de $T$. cruzi por via intraperitoneal (I.P) realizadas no $14^{\circ}$ dia, e com $8 \times 10^{5}$ formas tripomastigotas metacíclicas da mesma cepa para a infecção oral (I.O) no $21^{\circ}$ dia. Para todos os grupos utilizamos $n=5$. ${ }^{*} P<0,05$. 


\subsection{Análises fenotípicas das populações linfocitárias $\mathrm{CD4}^{+}$e $\mathrm{CD} 8^{+}$}

A avaliação de células linfocitárias $\mathrm{CD}^{+}$e $\mathrm{CD}^{+}$, foram realizadas com os esplenócitos colhidos durante o pico de parasitemia para ambas as vias de infecção.

$\mathrm{Na}$ infecção (I.P), o número de células $\mathrm{T} \mathrm{CD}^{+}$não apresentou aumento significativo quando comparado com a (I.O). Para células T CD8 ${ }^{+}$, não foi observado um aumento significativo no número destas células para a (I.O), quando comparado com (I.P). A infecção por via intraperitoneal e por via oral com a cepa $Y$ de $T$. cruzi apenas foi significativa sobre as células $\mathrm{CD} 4^{+}$e $\mathrm{CD} 8^{+}$quando comparadas ao grupo não infectado (C) (Figura 5).

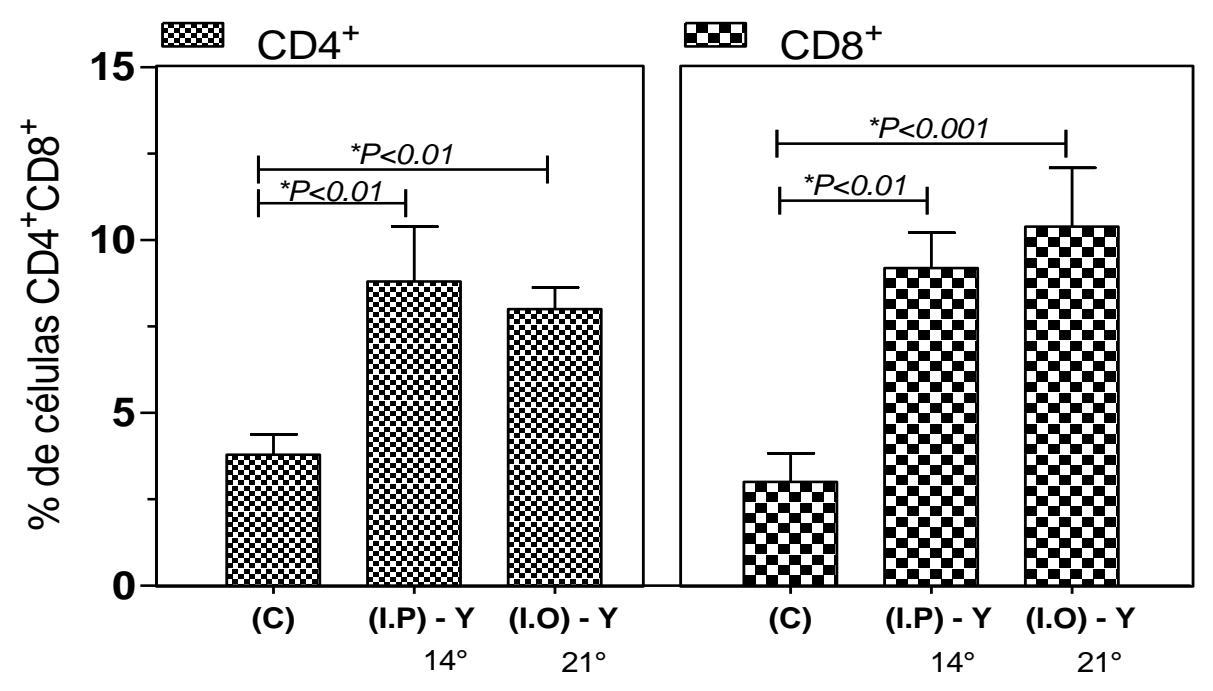

Curso da infecção intraperitoneal e oral

Figura 5: Aumento da população de linfócitos $\mathrm{T} \mathrm{CD4}^{+}$e $\mathrm{CD}^{+}$do baço de ratos Wistar machos infectados com $1 \times 10^{5}$ formas tripomastigotas metacíclicas da cepa $Y$ de $T$. cruzi por via intraperitoneal (I.P) realizadas no $14^{\circ}$ dia, e com $8 \times 10^{5}$ formas tripomastigotas metacíclicas da mesma cepa para a infecção oral (I.O) no $21^{\circ}$ dia. Para todos os grupos utilizamos $n=5$. * $P<0,05$. 


\subsection{Quantificação das concentrações de IFN - Y}

Um aumento estatisticamente significativo nas concentrações de IFN- $\gamma$ foi encontrado na infecção intraperitoneal (I.P), quando comparada com a infecção por via oral $(\mathrm{I} . \mathrm{O})(\mathrm{P}<0,05)$. Ambas as vias de infecção promoveram um aumento significativo nas concentrações de IFN- $\gamma$ quando comparado com o grupo controle $(\mathrm{P}<0,001$ e $\mathrm{P}<0,01)$ (Figura 6).

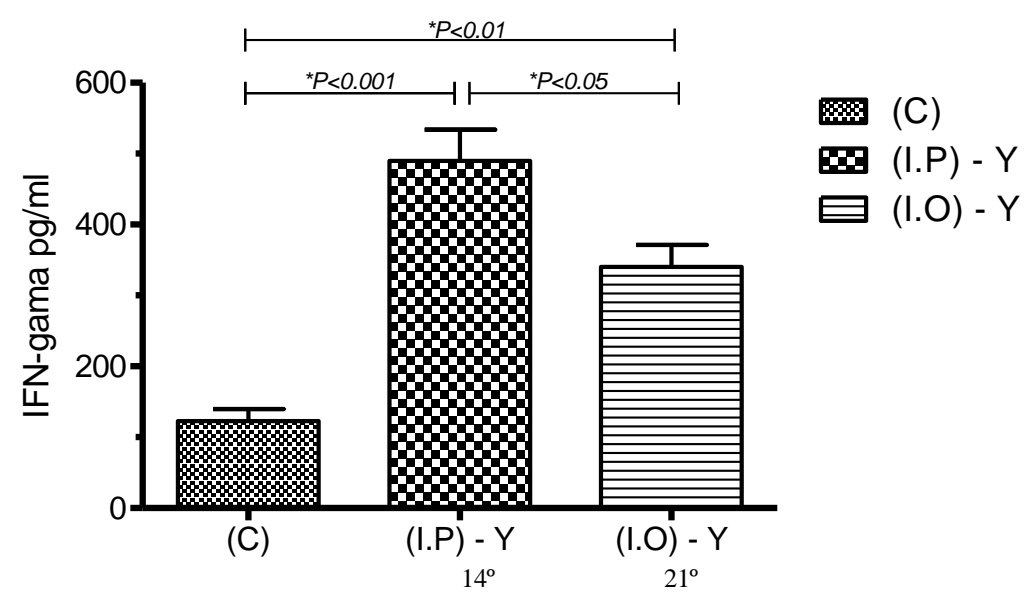

Dia de experimento

Figura 6: Aumento de IFN-y expresso em $\mathrm{pg} / \mathrm{ml}$ proveniente de soro de ratos Wistar machos infectados com $1 \times 10^{5}$ formas tripomastigotas metacíclicas da cepa $Y$ de $T$. cruzi por via intraperitoneal (I.P) realizadas no $14^{\circ}$ dia, e com $8 \times 10^{5}$ formas tripomastigotas metacíclicas da mesma cepa para a infecção oral (I.O) no $21^{\circ}$ dia. Para todos os grupos utilizamos $n=5$. ${ }^{*} \mathrm{P}<0,05$. 


\subsection{Quantificação das concentrações de Óxido Nítrico}

A produção de $\mathrm{NO}$ em ratos Wistar machos foi medida em células colhidas da cavidade peritoneal, no $14^{\circ}$ e $21^{\circ}$ dias após a infecção.

Para a infecção por via intraperitoneal (I.P), a concentração de NO foi significativamente maior quando comparado com a (I.O) $(\mathrm{P}<0,001)$. Ambas as rotas de infecção apresentaram produção significativa de óxido nítrico quando comparadas ao grupo controle não infectado (C) (Figura 7).

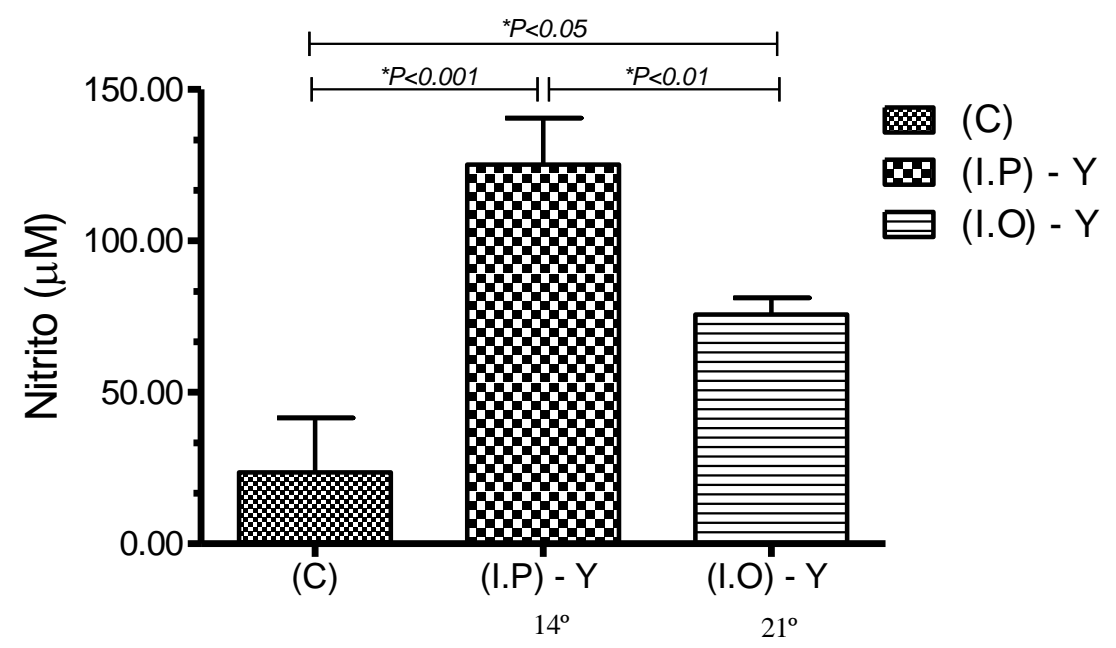

Dia de experimento

Figura 7: Concentração de nitrito expresso em $\mu \mathrm{M}$ em cavidade peritoneal de ratos Wistar machos infectados com $1 \times 10^{5}$ formas tripomastigotas metacíclicas da cepa $Y$ de $T$. cruzi por via intraperitoneal (I.P) realizadas no $14^{\circ}$ dia, e com $8 \times 10^{5}$ formas tripomastigotas metacíclicas da mesma cepa para a infecção oral (I.O) no $21^{\circ}$ dia. Para todos os grupos utilizamos $n=5$. ${ }^{*} P<0,05$. 


\subsection{Quantificação das concentrações de TNF- alpha}

O soro dos animais infectados pela via (I.P) não apresentaram aumento significativo nas concentrações do TNF- $\alpha$ quando comparado ao grupo infectado pela via (I.O). Entretanto, ambas as vias de infecção promoveram um aumento significativo nas concentrações de TNF- $\alpha$ quando comparados com o grupo controle $(\mathrm{P}<0,001)$ (Figura 8).

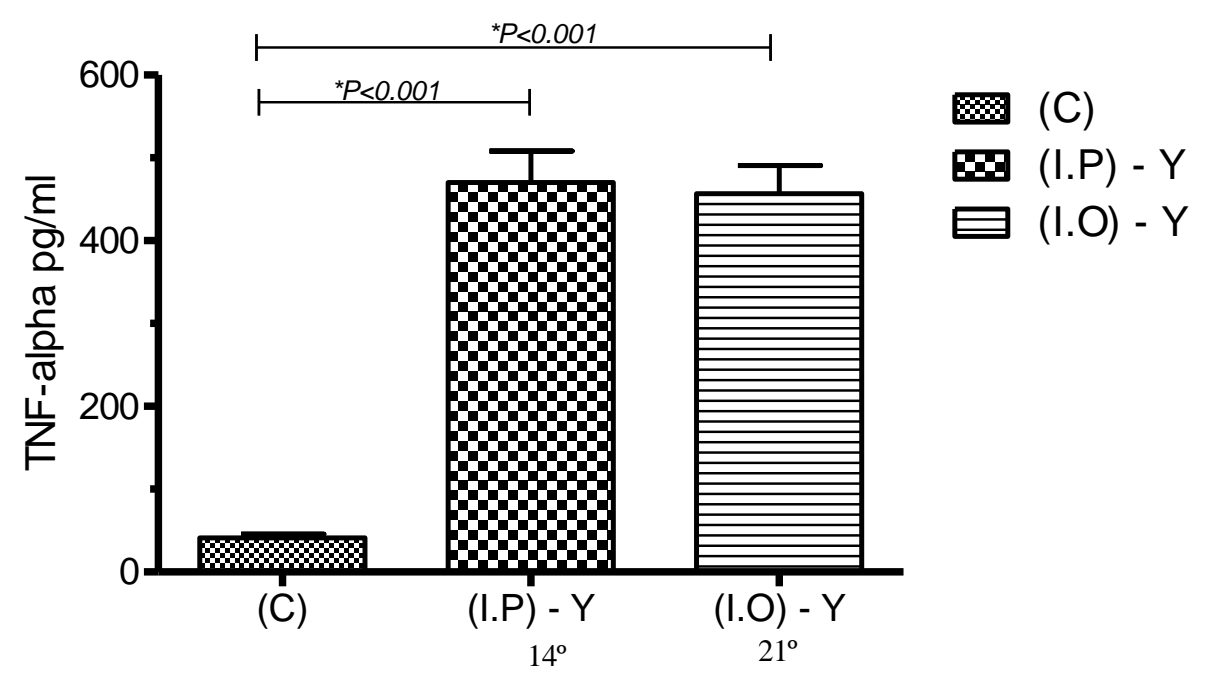

Dia de experimento

Figura 8: Produção de TNF- $\alpha$ expresso em pg/ml proveniente de soro de ratos Wistar machos infectados com $1 \times 10^{5}$ formas tripomastigotas metacíclicas da cepa $Y$ de $T$. cruzi por via intraperitoneal (I.P) realizadas no $14^{\circ}$ dia, e com $8 \times 10^{5}$ formas tripomastigotas metacíclicas da mesma cepa para a infecção oral (I.O) no $21^{\circ}$ dia. Para todos os grupos utilizamos $n=5$. * $P<0,05$. 


\subsection{Quantificação das concentrações de IL-12}

Para a infecção por via intraperitoneal (I.P), um aumento significativo nas concentrações de IL-12 foi maior quando comparado com à infecção oral (I.O) $(P<0,01)$.

Independentemente da via de infecção, acorreu aumento significativo nas concentrações de IL-12, quando comparado com o grupo controle (Figura 9).

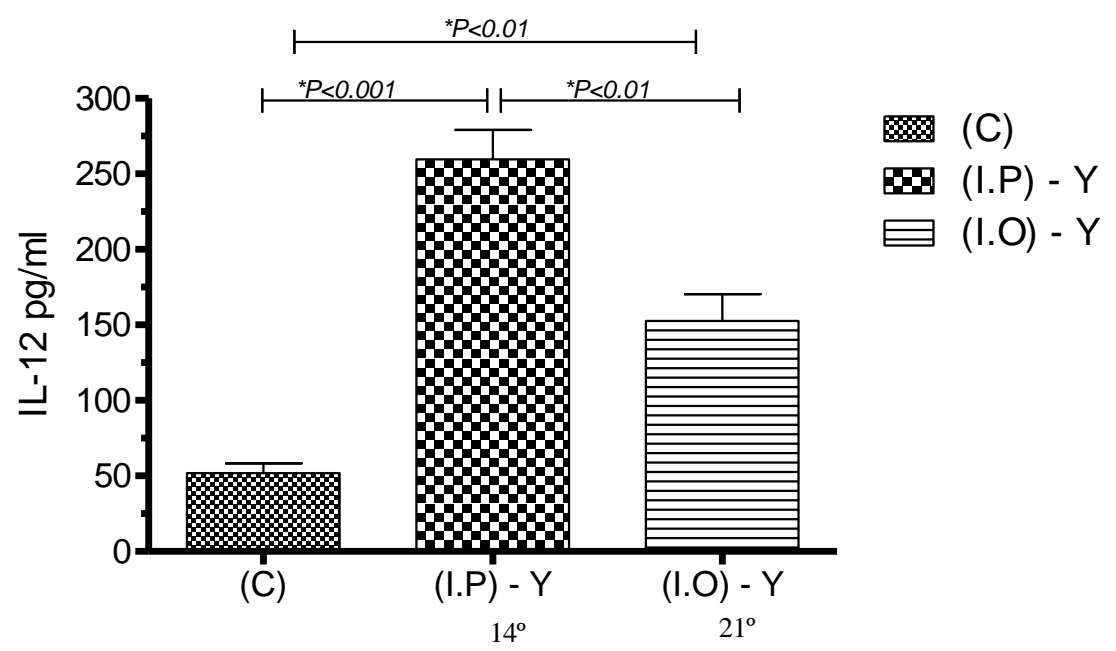

Dia de experimento

Figura 9: Produção de IL-12 expresso em $\mathrm{pg} / \mathrm{ml}$ proveniente do soro de ratos Wistar machos infectados com $1 \times 10^{5}$ formas tripomastigotas metacíclicas da cepa $Y$ de $T$. cruzi por via intraperitoneal (I.P) realizadas no $14^{\circ}$ dia, e com $8 \times 10^{5}$ formas tripomastigotas metacíclicas da mesma cepa para a infecção oral (I.O) no $21^{\circ}$ dia. Para todos os grupos utilizamos $n=5$. ${ }^{*} P<0,05$. 


\subsection{Quantificação das concentrações de IL-10}

Para a infecção por via intraperitoneal (I.P), não foi observado aumento significativo nas concentrações de IL-10 quando comparado com a infecção oral (I.O). Mas, independentemente da via de infecção, ambas demonstraram significativo aumento nas concentrações de IL-10, quando comparadas com o grupo controle $(P<0,01)$ (Figura 10).

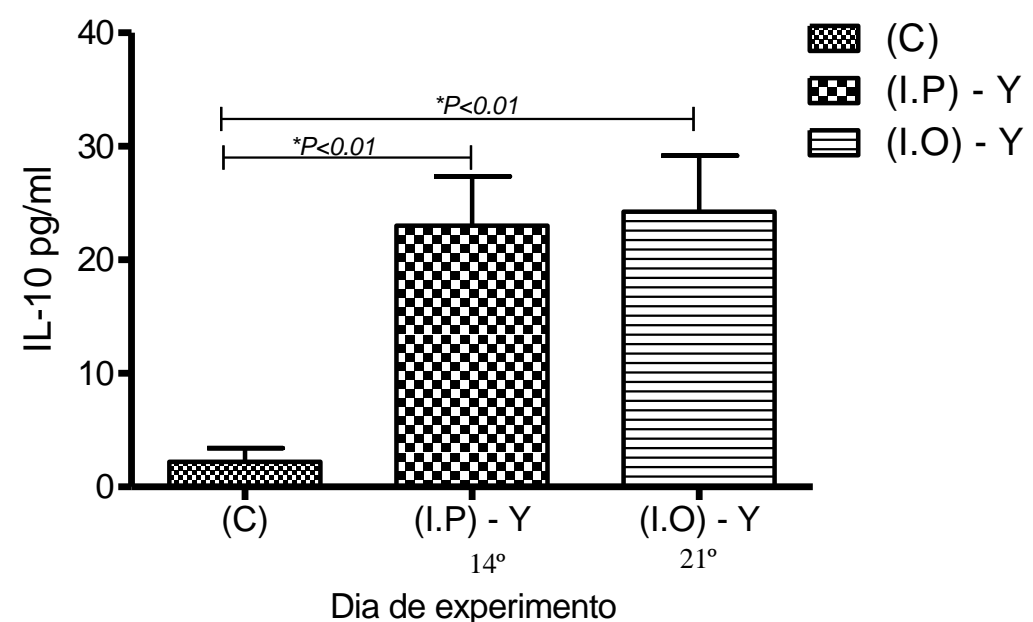

Figura 10: Produção de IL-10 expresso em $\mathrm{pg} / \mathrm{ml}$ proveniente de soro de ratos Wistar machos infectados com $1 \times 10^{5}$ formas tripomastigotas metacíclicas da cepa $Y$ de $T$. cruzi por via intraperitoneal (I.P) realizadas no $14^{\circ}$ dia, e com $8 \times 10^{5}$ formas tripomastigotas metacíclicas da mesma cepa para a infecção oral (I.O) no $21^{\circ}$ dia. Para todos os grupos utilizamos $n=5 .{ }^{*} P<0,05$. 


\subsection{Número de focos inflamatórios no coração}

Os corações dos animais infectados e controles não infectados foram removidos e a análise histopatológica do tecido cardíaco foi realizada em cortes corados com hematoxilina e eosina (400X).

Dessa forma, a (I.P), promoveu um aumento no número de focos inflamatórios quando comparado com a via oral com a cepa $Y$ de $T$. cruzi $(P<0,01)$ (Figura 11).
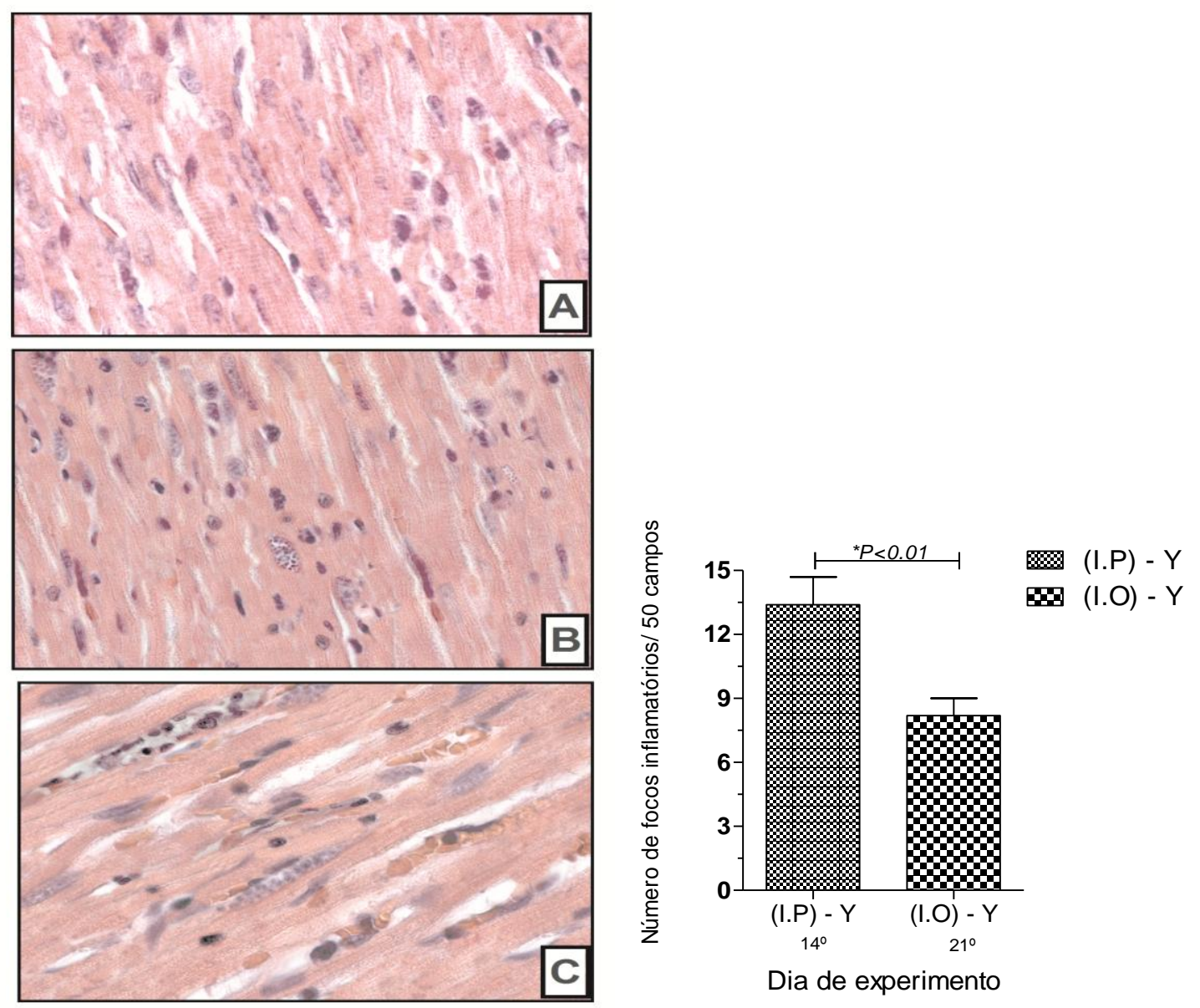

Figura 11: Aspectos histopatológicos observados em ratos Wistar machos infectados pela via intraperitoneal e oral com a cepa Y de T. cruzi. H \& E, 400X. A - Grupo controle sem parasitas e sem foco inflamatório. B - Infecção por via intraperitoneal. Seção do coração com miocardite intensa e foco inflamatório nas células do cardiomiócito. C- Infecção por via oral. Foco inflamatório moderado e miocardite com presença de parasitas nas células cardíacas. Cada barra representa a média \pm SD de um grupo experimental constituído por cinco animais. ${ }^{*} \mathrm{P}<0,05$ / B: (I.P) - Y vs C: (I.O) - Y, dia específico de experimento. 


\section{DISCUSSÃO}

Apesar de todos os avanços da ciência em adotar medidas profiláticas contra os vetores de uma doença, a transmissão vetorial continua sendo uma das principais rotas de contaminação por agentes patogênicos que afetam os seres humanos, tais como a malária, leishmaniose e tripanossomíase americana. Inúmeros estudos epidemiológicos, moleculares e imunológicos têm contribuído para uma melhor compreensão dos mecanismos relacionados a esta via de infecção, principalmente na doença de Chagas (COURA et al., 2002).

Os microrganismos patogênicos envolvidos nas infecções orais são poucos. Dentre estes patógenos, encontramos (Helicobacter pylori, Mycobacterium tuberculosis, Treponema pallidum, Histoplasma capsulatum) vírus tais como o citomegalovírus causador de granuloma gástrico em hospedeiros com má alimentação, alcoolismo e HIV (WANG E PEURA, 2011). Nesta via de infecção, alguns nematóides entéricos podem também estar envolvidos, como Anisakis simplex, Pseudoterranova decipiens e Strongyloides stercoralis, bem como o protozoário da doença de Chagas, Trypanosoma cruzi (OZTURK et al., 2011).

Nos últimos anos tem havido um aumento significativo de infecções orais por T. cruzi. Muitas vezes, estes acidentes estão relacionados à falta de inspeção sanitária dos alimentos que são consumidos pela população. No norte e nordeste aconteceram em 2007, ao redor de 177 casos de contaminação com caldo - de cana e açaí (CARLIER et al., 2002; DIAS, 1999).

Atento aos crescentes índices de infecção, ocorridos principalmente na região amazônica através das vias de infecção vetorial e oral da doença de Chagas, direcionamos nossos objetivos em uma melhor compreensão das diferentes respostas imunopatológicas de acordo com a via primária de infecção. Para tal o primeiro passo foi avaliar a parasitemia.

Durante a infecção por $T$. cruzi, o nível de parasitas no hospedeiro infectado está diretamente relacionado com a virulência da cepa, a carga parasitária, a imunidade do hospedeiro e do tipo de infecção. Na via vetorial, o parasito depara-se com a invasão de células do sistema imunitário. Por via oral, a superfície da mucosa gástrica se estabelece como a primeira barreira parasito/hospedeiro, sendo um ponto de entrada atraente para os diferentes agentes patogênicos, tais como HIV, 
tuberculose, helmintos e protozoários (NEUTRA E KOZLOWSKI, 2006; MATHERS et al., 2007; MONCADA et al., 2003).

Além disso, a transmissão vetorial por $T$. cruzi é mantido principalmente na natureza através de infecções orais entre várias espécies de animais, permitindo a continua circulação do parasito dentro do hospedeiro. COLLINS et al., (2011) relataram que uma infecção por $T$. cruzi pela via oral pode provocar nas mucosas uma resposta imunitária específica. Segundo ROUND E MAZMANIAN (2009), a magnitude da resposta imune do hospedeiro determinará o destino do parasito, assim como o nível de parasitemia sistêmica.

Diferentes autores sugeriram algumas possibilidades de como o sistema imunitário reconhece $T$. cruzi e o comportamento inicial do parasito ao atravessar a mucosa gástrica. Este evento é coordenado pela participação de glicoproteínas gp82 e gp30, bem como outras que são expressas na superfície dos tripomastigotas de quase todas as cepas de $T$. cruzi. Essas glicoproteínas são diretamente relacionadas à invasão da mucosa gástrica, através de co- receptores de membrana agonistas ao do parasito (NEIRA et al., 2003; YOSHIDA et al., 2000; COLLINS et al., 2011).

Nossos dados revelaram que no 14ํ dia pós - infecção, a (I.P) provocou um aumento estatisticamente significativo no número de tripomastigotas sanguíneos quando comparados à (I.O) no $21^{0}$ dia pós - infecção (Figura 3).

Os resultados obtidos em nossas análises corroboram os de CAMANDAROBA et al., (2002), em modelos murinos infectados pela via intraperitoneal e oral com as cepas Peruvian e Colombian de T. cruzi. Os autores mostraram que específicas vias de infecção e diferentes cepas induziram distintos níveis de parasitemia, bem como diversas alterações patológicas no hospedeiro.

Várias hipóteses podem explicar os diferentes níveis de parasitemia entre as infecções vetoriais e orais, correlacionando a presença das glicoproteinas e o sistema imunológico do hospedeiro. Os estudos de GOODRICH E MCGEE, 1998 e YAMAMOTO et al., 1996 sugerem que o primeiro contato entre a mucosa e o parasita promovem uma resposta imune tipo Th-2 e a produção de $\lg A$, a qual é responsável pela proteção contra o parasito. Outros estudos relatam que uma deficiência de gp82 em tripomastigotas metacíclicos reduz o grau de infecção na mucosa gástrica e a capacidade das células hospedeiras em internalizar o parasito (CORTES et al., 2003; YOSHIDA et al., 2006; YOSHIDA, 2009). 
De acordo com EICKHOFF et al., (2010), gp82 é fundamental para a invasão de células, sendo um alvo principal do sistema imune. YOSHIDA et al., (2006) relatam que essa proteína é preservada em quase todas as cepas de T. cruzi, incluindo Y, CL, F e Tulahuén. Portanto, a hipótese de que a menor parasitemia durante a inoculação por via oral pode ser uma consequência de alguns fatores tais como o aumento dos níveis de anticorpos e infiltrados mononucleares dirigidos contra a proteína ou a diminuição da expressão de gp82 pelo parasito.

Após o estabelecimento de uma infecção por $T$. cruzi, várias células imunológicas são ativadas através de glicoproteínas específicas. Macrófagos, células $\mathrm{T}$ e citocinas trabalham juntos para controlar a replicação parasitária durante a infecção (COSTA et al., 2006, PADILLA et al., 2007, TALIAFERRO E PIZZI, 1955).

A imunidade inata é a primeira linha de defesa contra microorganismos invasores. As células da linhagem monocítica estão diretamente envolvidas no controle do parasito durante as fases iniciais de infecção com $T$. cruzi in vivo e in vitro (REYES et al., 2006, BRUNET et al., 2001, KUEHN et al., 2011). Classicamente macrófagos ativados estão envolvidos na sinalização de células T virgens CD4+ e CD8+, que sintetizam mediadores inflamatórios tais como IFN- $\mathrm{\gamma}, \mathrm{IL}-12, \mathrm{TNF}-\alpha, \mathrm{IL}-10$ e aumento na produção de NO (CAMUSSI et al., 1991, BRAZÃO et al., 2011).

Os trabalhos acima citados corroboram de forma indireta com nossos dados onde a via de infecção (I.P) apresentou um aumento significativo no número de macrófagos peritoneais em relação à (I.O). Ambas as vias de infecção foram capazes de estimular as células mononucleares na tentativa de controlar a parasitemia (Figura 4).

As interações complexas que ocorrem entre as células durante a infecção por T. cruzi desempenham um papel crítico no percurso da doença. Os macrófagos podem estar envolvidos tanto em atividades fagocíticas/secretoras, bem como na produção de nitrogênio e oxigênio reativo intermediário (MACMICKING et al., 1997).

Os macrófagos também apresentam os antígenos via complexo principal de histocompatibilidade ( $\mathrm{MHC})$ de classe I e classe II em sua superfície. Peptídeos microbianos, ligados a macrófagos ativam células T CD4+ e CD8+ para produzir imunidade inata e adaptativa (MEDZHITOV E JANEWAY, 1999).

Provavelmente em virtude destes diferentes mecanismos de invasão e de reconhecimento das glicoproteínas durante a infecção oral, os modelos murinos conseguiram montar uma resposta imune Th-1 normal. Isto também poderia explicar 
a parasitemia inferior encontrada nos animais infectados pela via oral. Nossos dados mostram claramente uma contagem mais baixa de macrófagos quando o parasita foi administrado pela via oral durante a fase aguda da infecção. As propriedades microbicidas e a ativação imunitária do hospedeiro estão sempre ligadas à destruição de inúmeros patógenos. Apesar da complexa estrutura montada contra o parasito, é notável que diversos protozoários invadam, sobrevivam e repliquem-se com êxito dentro destas células.

ZHANG E TARLETON (1999) relatam que a resposta imune do hospedeiro ativa distintas subpopulações de linfócitos $T$ durante a infecção aguda. Isto foi observado em nosso experimento, com discreto aumento no nível de células T CD4+ para (I.P) e células T CD8+ para (I.O). Apesar deste perfil aumentado, as diferenças eram estatisticamente significativas apenas quando comparado com o grupo controle (Figura 5).

De acordo com PEREZ et al., 2012, as células T que expressam coreceptores CD4+ e CD8+ foram descritos em indivíduos saudáveis bem como em pacientes que sofrem de condições patológicas, incluindo doenças infecciosas, autoimunes e processos inflamatórias crônicos. A maioria das células T CD4+ e CD8+ sofrem diferenciação para células $T$ maduras no timo. No entanto, durante a infecção por T. cruzi, o timo é severamente afetado por uma cascata desregulada de citocinas pró-inflamatórias e hormônios relacionados ao hipotálamo, hipófise e adrenal (CORREA-DE-SANTANA et al., 2006; PEREZ et al., 2007).

Portanto, a ativação excessiva do sistema imunitário pode contribuir para a disfunção imune patológica na doença de Chagas (FIUZA et al., 2009). Uma possível explicação para este desequilíbrio imunológico nas populações de células $T$ CD4+ e CD8+ pode estar relacionados com os antígenos libertados por parasitos mortos no estômago, que são subsequentemente transportados para placas de Peyer do intestino delgado. Estes antígenos estimulam linfócitos de memória circulantes, criando uma resposta imunitária sistêmica, como resultado de uma infecção por via oral (HOFT et al., 1996, SCHMAUSSER et al., 2004). O fato das subpopulações de células T CD4+ e CD8+ não apresentarem diferenças significativas em nossos resultados pode estar relacionada a uma resposta imunitária desequilibrada, desencadeada por antígenos de parasitos, que recrutaram linfócitos de memória, reduzindo assim, a capacidade destas células em se proliferar. 
A relação imunológica entre os tipos de infecção pode ser observada em nossos resultados. Concentrações estatisticamente mais elevadas de IFN- $\gamma$ foram observados na (I.P) comparada a (I.O), sugerindo que a resposta imune tipo I sistêmica foi ativada de maneira mais efetiva (Figura 6).

A combinação da imunidade da mucosa e sistêmica podem maximizar a proteção contra muitas doenças crônicas provocadas por agentes patogênicos intracelulares nas mucosas (por exemplo, T. cruzi, Mycobacterium tuberculosis, e o HIV) (HOFT E EICKHOFF, 2005). O fato de termos um aumento de IFN- $\gamma$ quando administrado pela via (I.P) pode ser explicada pela premissa de que a proteção da mucosa e sistêmica requer diferentes respostas imunes. Quando as células T produzem interleucina-4 (IL-4), IL-5 e IL-10 (fenótipo tipo 2) ou níveis elevados de fator de transformação do crescimento $\beta$ (TGF- $\beta$; fenótipo de tipo 3 ), a secreção de imunoglobulina $A$ é induzida e promove a proteção da mucosa contra a infecção (YAMAMOTO et al., 1996, GOODRICH et al., 1998). Ao contrário, as células T produtoras de IFN- $\gamma$, TNF- $\alpha$ e IL-2 (fenótipo tipo 1) desempenham um papel protetor contra a replicação intracelular sistêmica de muitos agentes patogênicos humanos (O'GARRA, 1998). Assim, os trabalhos anteriores corroboram indiretamente com nossos dados, porque níveis aumentados de IFN- $y$ foram encontrados durante a (I.P).

Diversas outra interleucinas, como o IFN- $y$ citada por GAZZINELLI et al., 1992, SILVA et al., 1995, estão envolvidas no processo de infecção por T. cruzi. A ativação de macrófagos por estes parasitos intracelulares, como mencionado anteriormente, pode estimular mecanismos que desencadeiam a síntese destas reações como, por exemplo, o óxido nítrico encontrado em ambas as infecções, porém a I.P promoveu concentrações estatisticamente mais elevadas quando comparadas com a I.O e grupo controle (Figura 7).

Em nossos resultados o TNF-alpha apresentou um aumento tanto na infecção (I.P) como na (I.O), entretanto valores estatisticamente significativos apenas foram observados quando comparados ao grupo controle (Figura 8).

Pesquisas pioneiras como de TARLETON et al., (1988) já demonstravam que T. cruzi é um agente etiológico capaz de induzir a síntese de TNF- a tanto em infecções in vivo como in vitro. De acordo com DOS-REIS (1997), a produção de TNF- a por macrófagos pode ajudar no controle da parasitemia, entretanto em 
excesso causa lesões tóxicas, principalmente em tecidos cardíacos na fase aguda da doença.

TRUYENS et al., (1999) analisando a parasitema em ratos infectados pela via intraperitoneal com T. cruzi, identificou altos níveis de TNF- $\alpha$ associado a um papel benéfico no inicio da infecção. Não se sabe ao certo quais os reais motivos da elevada concentração de TNF- a na (I.O), entretanto baseado nos trabalhos de HOFT et al., (2000) acreditamos que um estímulo prévio da infecção oral no epitélio estomacal através de $T$. cruzi pode desencadear uma produção de interleucinas Th-1.

Quanto as interleucinas IL-12 e IL-10 observamos discretas modulações em nosso estudo. IL-12, uma citocina Th-1, apresentou concentrações aumentadas durante a (I.P) em comparação com a (I.O) (Figura 9). No entanto, a IL-10 uma citocina Th-2, apresentou um aumento discreto, sem significância estatística na I.O em relação a I.P, porém, ambas as infecções apresentaram concentrações estatisticamente mais elevadas quando comparadas com o grupo controle (Figura 10).

Algumas citocinas de importância já foram identificadas na geração de diferentes subpopulações de células $T$. Por exemplo, a IL-12 e IL-4 são fundamentais para a indução da respectiva resposta tipo 1 e 2 (O'GARRA, 1998). HOFT E EICKHOFF (2005) demonstraram que a IL-12 recombinante e anti-IL-4 induziram respostas do tipo 1 in vivo, sendo altamente protetoras contra cepas letais de $T$. cruzi quando por ocasião da infecção oral. Vários outros trabalhos demonstraram que uma resposta Th-1 contribui para o desenvolvimento de alterações patológicas durante a infecção intraperitoneal com T. cruzi. Assim, 0

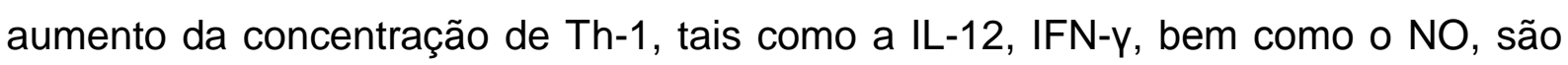
de importância vital para controlar a replicação do parasita durante a fase aguda. Em uma ação primária, estas substâncias desencadeiam uma ativação de células NK na produção de IFN-y, que por sua vez estimula macrófagos a sintetizar NO com atividade antiviral, antimicrobiana e antiparasitária (CLARK E ROCKETT, 1996; PINSKY et al., 1999, OLIVEIRA et al., 2000).

O aumento nas concentrações de IL-12 encontrado na (I.P) corrobora as afirmações descritas anteriormente. O mesmo pode ser explicado para IL-10, embora diferenças significativas não tenham sido encontradas entre (I.P) e (I.O). O aumento discreto na concentração de IL-10 durante a (I.O), poderia contribuir para uma resposta polarizada tipo 2 compatível com a infecção oral, advindas do perfil 
imune promovidos nas célula estomacais após a infecção do parasito (HOFT et al., 2000; SCHNAPP et al., 2000).

As análises histopatológicas no tecido cardíaco revelaram um padrão distinto na colonização de parasitas, na qual a (I.P) exibiu um moderado infiltrado inflamatório com vários ninhos de amastigotas. Para a (I.O) discretos ninhos de amastigotas e células inflamatórias foram observadas, porém mantendo a arquitetura celular cardíaca (Figura 11). Os mecanismos precisos promovidos pelo sistema imunológico para controlar a disseminação dos tripomastigotas inoculados oralmente não são bem definidos, embora acreditamos que a carga de parasitos foi muito mais alta na (I.P), propiciando o aparecimento de uma maior resposta do tipo 1. Consequentemente, a entrada de tripomastigotas nos cardiomiócitos, provocaram um aumento dos ninhos de amastigotas entre as fibras cardíacas, seguidas por um aumento no infiltrado inflamatório. O oposto ocorreu na (I.O), apesar de provocar uma resposta imunológica Th-2 que limitou a invasão do parasita, a carga parasitária foi menor devido às barreiras que os tripomastigotas metacíclicos tiveram que atravessar, a fim de estabelecer-se e dividir-se em macrófagos locais. É importante ressaltar que ambos os tipos de infecção tinham a capacidade de promover o dano cardíaco. No entanto, a via de infecção foi crucial em causar miocardite aguda.

Nossos dados corroboram os de CAMANDAROBA et al., (2002), que usaram modelos murinos, infectados pela via oral e intraperitoneal com diferentes cepas de $T$. cruzi. Os autores descreveram alterações significativas nos níveis de parasitemia e de miocardite, dependendo o tipo de infecção e a cepa utilizada.

Nossos resultados demonstraram que a infecção oral pode por si mesma estabelecer-se em uma infecção sistêmica e que diferentes vias de inoculação promovem distintos tipos de resposta imune. Isto foi observado pelo aumento de ninhos de amastigostas e células inflamatórias nas análises histopatológicas. Entretanto, as respostas imunopatológicas geradas contra anti- $T$. cruzi na infecção intraperitoneal ou oral não forneceram dados suficientes para distinguir entre os dois tipos de inoculação provocados inicialmente.

A obtenção desses parâmetros certamente contribuiu para um melhor entendimento das respostas imunes promovidas por $T$. cruzi e da patogenia relacionada à disfunção cardíaca chagásica aguda, geradas durante as duas vias de infecção. 


\section{CONCLUSÃO}

Analisando os dados apresentados, concluímos que:

$\checkmark$ O T. cruzi foi capaz de sobreviver na polpa de açaí por diferentes períodos de incubação, além de preservar a sua virulência em ratos. Esse fato é de importância epidemiológica e descarta os processos de refrigeração convencionais, durante os períodos de tempo testados, como método de controle da transmissão oral da doença de Chagas aguda.

$\checkmark \mathrm{Na}$ análise de parasitemia, a intensidade ou a presença do parasito pode estar influenciada diretamente pela via de inoculação e suas barreiras naturais, como observado na inoculação por via oral, que apresentou uma carga parasitaria menor que na I.P. Este fato pode estar relacionado com os possíveis níveis de anticorpos e infiltrados mononucleares dirigidos contra a proteína ou a diminuição da expressão de gp82 pelo parasito.

A proliferação de macrófagos peritoneais manteve-se mais efetiva quando administrado I.P.

$\checkmark$ Um significativo aumento no nível de células T CD4+ e T CD8+ foi observado em ambos modelos experimentais, ou seja, infectados pela via intraperitoneal ou oral.

$\checkmark$ Os valores elevados das interleucinas tipo Th- 1 sugerem que ambas as vias de inoculação podem promover um quadro de infecção contra o $T$. cruzi. Porém a via I.P apresentou uma produção mais elevada quando comprada a I.O. Analisando a interleucina tipo Th-2, a mesma apresentou um aumento discreto (não estatístico) na I.O sobre a I.P.

As análises histopatológicas no tecido do coração demonstraram um padrão distinto na colonização de parasitas, na qual a I.P exibiu um moderado infiltrado inflamatório com vários ninhos de amastigotas. Na I.O foi observada a presença de discretos ninhos de amastigotas e células inflamatórias, porém a arquitetura celular cardíaca manteve-se preservada. 
Sendo assim, estes resultados demonstram que ambas as vias de inoculação podem promover um quadro imunopatológico. Entretanto, não fornecem dados suficientes para distinguir entre os dois tipos de inoculação. 


\section{REFERÊNCIAS}

ALIBERTI, J. C. S.; CARDOSO, M. A. A. G.; MARTINS, G. A.; GAZZINELI, R. T.; VIEIRA, L. Q.; SILVA, J. S. Interleukin - 12 mediates resistance to Trypanosoma cruzi in mice and in produced by murine macrophages in response to live trypomastigotes. Infection and Immunity, Estados Unidos, v. 64, p. 1961-1967, 1996.

ALIBERTI, J. C. S.; MACHADO, F. S.; SOUTO, J. T. Beta - chemokines enhance parasite uptake and promete nitric oxide-dependent microbiostatic activity in murine inflammatory macrophages infected with Trypanosoma cruzi. Infection and Immunity, Estados Unidos, v. 67, p. 4819-4826, 1999.

ANDRADE, S. G. Morphological and behavioral characterization of Trypanosoma cruzi strains. Revista da Sociedade Brasileira de Medicina Tropical, Brasil, v.18, p. 39-46, 1985.

ANDRADE, S. G.; CARVALHO, M. L.; FIGUEIRA, R. M. Caracterização morfobiológica e histopatológica de diferentes cepas do Trypanosoma cruzi. Gazeta Médica da Bahia, Brasil, v. 70, p. 32-42, 1970.

ANDRADE, S. G.; MAGALHÃES, J. B. Biodemes and zymodemes of Trypanosoma cruzi strains: correlations with clinical data and experimental pathology. Revista da Sociedade Brasileira de Medicina Tropical, Brasil, v. 30, p. 27-35, 1997.

AMATO, N. V.; LOPES, M. H.; UMEZAWA, E. S.; RUOCCO, R. M. S. A.; DIAS, J. C. P. Outras formas de transmissão do Trypanosoma cruzi. Revista de Patologia Tropical, Brasil, v. 29, p. 115-130, 2000.

BARBOSA, R. L.; DIAS, V. L.; PEREIRA, K. S.; SCHMIDT, F. L.; FRANCO, R. M.; GUARALDO, A. M.; ALVES, D. P.; PASSOS, L. A. Survival in vitro and virulence of Trypanosoma cruzi in açaí pulp in experimental acute Chagas disease. Journal of Food Protection, Estados Unidos, v. 75, p. 601-6, 2012.

BRAZÃO, V.; FILIPIN, M. D. V.; SANTELLO, F. H; CAETANO, L. C.; ABRAHÃO, A. A. C.; TOLDO, M. O. A.; PRADO, J. C. Melatonin and zinc treatment: distinctive modulation of cytokine production in chronic experimental Trypanosoma cruzi infection. Cytokine, Estados Unidos, v. 56, p. 627-632, 2011. doi: 10.1016/j.cyto.2011.08.037.

BRENER, Z. Therapeutic activity and criterion of cure in mice experimentally infected with Trypanosoma cruzi. Revista do Instituto de Medicina Tropical, Brasil, v. 4, p. 389-396, 1962. 
BRENER, Z.; CHIARI E. Variações morfológicas observadas em diferentes amostras de Trypanosoma cruzi. Revista do Instituto de Medicina Tropical, Brasil, v. 5, p. 220-224, 1963.

BRUNET, L. R. Review-nitric oxide in parasitic infections. International Immunopharmacology, Holanda, v. 1, p. 1457-1467, 2001. doi.org/10.1016/S15675769(01)00090-X.

CALDEIRA, J. C.; FRANCI, C. R. Prolactin and Corticosterone secretion in response to acute stress after paraventricular nucleus lesion by ibotenic acid. Brain Research Bulletin, Estados Unidos, v. 52, p. 483-489, 2000.

CAMANDAROBA, L. E. P.; LIMA, C. P.; ANDRADE S. G. Oral transmission of Chagas disease: Importance of Trypanosoma cruzi biodeme in the intragastric experimental infection. Revista do Instituto de Medicina Tropical de São Paulo, Brasil, v. 44, p. 97-103, 2002. doi:10.1590/S0036-46652002000200008.

CAMARGO, E. R. S.; FRANCO, D. J.; GARCIA, C. M. M. G.; DUTRA, A. P.; TEXEIRA JÚNIOR, A. L.; CHIARI, E.; MACHADO, C. R. S. Infection with different Trypanosoma cruzi populations in rats: myocarditis, cardiac sympathetic denervation and involvement of digestive organs. The American Journal of Tropical Medicine and Hygiene, Estados Unidos, v. 62, p. 604-12, 2000.

CAMUSSI, G.; ALBANO, E.; TETTA, C.; BUSSOLINO, F. The molecular action of tumor-necrosis-factor-alpha. European Journal of Biochemistry, Inglaterra, v. 202, p. 3-14, 1991. doi: 10.1111/j.1432-1033.1991.tb16337.x.

CARLIER, Y.; DIAS, J. C. P.; LUQUETTI, A. O.; HONTEBEYRIE, M.; TORRICO, F.; TRUYENS, C. Trypanosomiase americane ou maladie de Chagas. Enciclopédia Médico-Cirúrgico, Brasil, v. 8, p. 505-A20, 2002.

CHAGAS, C. "Nova tripanozomiaze humana". Memórias do Instituto Oswaldo Cruz, Brasil, v. 1, n. 2, p. 9-80, 1909.

COVARRUBIAS, C.; MAURO, C.; DANIELE, F.; NOBUKO Y. Interaction with host factors exacerbates Trypanosoma cruzi cell invasion capacity upon oral infection. International Journal for Parasitology. Inglaterra, v. 37, p. 1609-1616, 2007.

CLARK, I. A.; ROCKETT, K. A. Nitric oxide and parasitic disease. Advances in Parasitology, Inglaterra, v. 37, p. 1-56, 1996.

COLLINS, M. H.; CRAFT, J. M.; BUSTAMANTE, J. M.; TARLETON, R. L. Oral exposure to Trypanosoma cruzi elicits a systemic CD8+ T Cell Response and Protection against Heterotopic Challenge. Infection and Immunity, Estados Unidos, v. 79, p. 3397-3406, 2011. doi: 10.1128/IAI.01080-10. 
CORREA-DE-SANTANA, E.; PAEZ-PEREDA, M.; THEODOROPOULOU, M.; KENJI NIHEI, O.; GRUEBLER, Y.; BOZZA, M.; ARZT, E.; VILLA-VERDE, D. M.; RENNER, U.; STALLA, J.; STALLA, G. K.; SAVINO, W. Hypothalamus-pituitary-adrenal axis during Trypanosoma cruzi acute infection in mice, Journal of Neuroimmunology, Holanda, v. 173, p. 12-22, 2006. doi:10.1016/j.jneuroim.2005.08.015.

COSTA, V. M; TORRES, K. C; MENDONÇA, R. Z; GRESSER, I.; GOLLOB, K. J; ABRAHAMSOHN, I. A. Type I IFNs stimulate nitric oxide production and resistance to Trypanosoma cruzi infection. Journal Immunology, v. 177, p. 193-200, 2006.

COURA, J. R; JUNQUEIRA, A. C. V.; FERNANDES, O.; VALENTE S. A. S.; MILES M. A. S. Emerging Chagas disease in Amazonian Brasil. Trends Parasitol., Inglaterra, v. 18, p. 171-176, 2002.

COURA, J. R.; DIAS, J. C. P. Memórias do Instituto Oswaldo Cruz, Brasil, v. 104 (suppl. 1), p. 31-40, 2009.

CORTEZ, M.; NEIRA, I.; FERREIRA, D.; LUQUETTI, A. O.; RASSI, A.; ATAYDE, V. D.; YOSHIDA, N. Infection by Trypanosoma cruzi metacyclic forms deficient in gp82 but expressing a related surface molecule gp30. Infection and Immunity, Estados Unidos, v. 71, p. 6184-6191, 2003.

DEVERA, R; ILLIRRAMENDI, $\quad \mathrm{X}$; MONTOYA-ARAÚJO, R; PIRMEZ, C; FERNANDES, O; COURA, JR. Biodemas de cepas de Trypanosoma cruzi isoladas de humanos de três áreas endêmicas de Minas Gerais. Revista da Sociedade Brasileira de Medicina Tropical, Brasil, v. 35, p. 323-330, 2002.

DEANE, M. P. Significance of polymorphismo in Trypanosoma cruzi. In: CONGRESSO INTERNACIONAL SOBRE DONEÇA DE CHAGAS. Fundação Oswaldo Cruz, Brasil, Anais/Abstracts, p. A6-A7, 1979.

DIAS, J. C. P. Epidemiologia. In: Trypanosoma cruzi e Doença de Chagas (Z. Brener, Z. A. Andrade; M. Barral Netto, org., p. 48-74, 1999. Editora Guanabara Koogan, Rio de Janeiro, Brasil.

DIAZ-UNGRÍA, C. Estudio experimental del Trypanosoma cruzi en el perro y otros vertebrados. El problema de La transmisión. Kasmera, Venezuela, v. 3, p. 7388,1968 .

DIAS, J. C. P.; ANDRADE, Z. A.; BARRAL, N. Epidemiologia. In: Brener M. (orgs) Trypanosoma cruzi e doença de Chagas. Editora Guanbara Koogan, Brasil, p. 48$74,2000$. 
DOS-REIS, G. Cell-mediated immunity in experimental Trypanosoma cruzi infection. Parasitol Today, Inglaterra, v. 13, p. 335-342, 1997.

EICKHOFF, C. S; GIDDINGSA, O. K.; YOSHIDA, N.; HOFT, D. F. Immune responses to gp82 provide protection against mucosal Trypanosoma cruzi infection. Memórias do Instituto Oswaldo Cruz, Brasil, v. 105, p. 687-691, 2010.

FIUZA, J. A.; FUJIWARA, R. T.; GOMES, J. A.; ROCHA, M. O.; CHAVES, A. T.; DE ARAÚJO, F. F. Profile of central and effector memory T cells in the progression of chronic human chagas disease. PLoS Neglected Tropical Diseases, Estados Unidos, v. 3, p. e512, 2009. doi: 10.1371/journal.pntd.0000512.

HOFT, D. F.; SCHNAPP, A. R; EICKHOFF, C. S; ROODMAN, S. T; Involvement of CD4_Th1 cells in systemic immunity protective against primary and secondary challenges with Trypanosoma cruzi. Infection and Immunity, Estados Unidos, v. 68, p. 197-204, 2000. doi: 10.1128/IAI.68.1.197-204.2000.

HOFT, D. F.; FARRAR, P. L.; KRATZ-OWENS, K.; SHAFFER, D. Gastric invasion by Trypanosoma cruzi and induction of protective mucosal immune responses Infection and Immunity, Estados Unidos, v. 64, p. 3800-3810, 1996.

HOFT, D. F.; EICKHOFF, C. S. Type 1 immunity provides both optimal mucosal and systemic protection against a mucosally invasive, intracellular pathogen. Infection and Immunity, Estados Unidos, v. 70, p. 4934-4940, 2005. doi: 10.1128/IAI.73.8.4934-4940.2005.

HOFT, D. F.; SCHNAPP, A. R.; EICKHOFF, C. S.; ROODMAN, S. T. Involvement of CD4_Th1 cells in systemic immunity protective against primary and secondary challenges with Trypanosoma cruzi Infection and Immunity, Estados Unidos, v. 68, p. 197-204, 2000. doi: 10.1128/IAI.68.1.197-204.2000.

KUEHN, C.C.; OLIVEIRA, L. G. R.; SANTOS, C. D.; AUGUSTO, M. B.; TOLDO, M. P. A.; PRADO JR, J. C. Prior and concomitant Dehydroepiandrosterone treatment affects immunologic response of cultured macrophages infected with Trypanosoma cruzi in vitro? Veterinary Parasitology, Holanda, v. 177, p. 242-246, 2011. doi: 10.1016/j.vetpar.2010.12.009.

GARCIA, S. B.; PAULA, J. S.; GIOVANETTI, G. S.; ZENHA, F.; RAMALHO, E. M.; ZUCOLOTO, S.; SILVA, J. S.; CUNHA, F. Q. Nitric oxide is involved in the lesions of the peripheral autonomic neurons observed in the acute phase of experimental Trypanosoma cruzi infection. Experimental Parasitology, Estados Unidos, v. 93, p. 191-197, 1999. 
GAZZINELLI, R. T.; OSWALD, I. P.; HIENY, S.; JAMES, S. L.; SHER, A. Microbicidal activity of interferon-gamma-treated macrophages against Trypanosoma cruzi involves an L-arginine-dependent, nitrogen oxide-mediated mechanism inhibitable by interleukin-10 and transforming growth factor-beta. The European Journal of Immunology, Alemanha, v. 22, p. 2501-2506, 1992.

GIORDIANO R.; CHAMMAS, R.; VEIGA, S. S.; COLLI, W.; ALVES, M. J. M. An acidic component of the heterogeneous Tc-85 protein family from the surface of Trypanosoma cruzi is a laminin binding glycoprotein. Molecular and Biochemical Parasitology, Holanda, v. 65, p. 85-94, 1994.

GOODRICH, M. E.; MCGEE, D. W. Regulation of mucosal B cell immunoglobulin secretion by intestinal epithelial cell-derived cytokines. Cytokine, Estados Unidos, v. 10, p. 948-955, 1998. .doi: 10.1006/cyto.1998.0385.

GRELLIER P., ET AL. Trypanosoma cruzi prolyl oligopeptidase Tc80 is involved in nonphagocytic mammalian cell invasion by trypomatigotes. The Journal of Chemical Biology, Alemanha, v. 276, p. 47078-47080, 2001.

IANNI, BARBARA MARIA; MADY, C. Como era gostoso o meu caldo de cana. Arquivos Brasileiros de Cardiologia, Brasil, v. 85, p. 379-381, 2005.

KROPF, S. P.; FERREIRA, N. A. L. O. Doença de Chagas: a construção de um fato científico e de um problema de saúde pública no Brasil. Ciência e Saúde Coletiva, Brasil, v. 5, p. 347-365, 2000.

LOPES, E. R.; CHAPADEIRO, E. Pathogenesis of American Tryapanosomiasis. In: Maudlin, I.; Holmes, P.; Miles, M. A.; The tripanosomes. CABI International, Londres, p. 303-330, 2004.

MACMICKING, J.; XIE, Q. W.; NATHAN, C. Nitric oxide and macrophage function. Annual Review of Immunology, Estados Unidos, v. 15, p. 323-350, 1997. doi: 10.1146/annurev.immunol.15.1.323.

MAGDESIAN, M. H.; GIORDANO, R.; JULIANO, M. A.; JULIANO, L.; SCHUMACHER, R. I.; COLLI, W.; ALVES, M. J. M. Infection by Trypanosoma cruzi: identification of a parasite ligand and its host-cell receptor. Journal of Biological Chemistry, v. 276, p. 19382-19389, 2001.

MÁLAGA, S.; YOSHIDA, N. Targeted reduction in expression of Trypanosoma cruzi surface glycoprotein gp90 increases parasite infectivity. Infection and Immunity, Estados Unidos, v. 69, p. 353-359, 2001. 
MATHERS, C. D.; EZZATI, M.; LOPEZ, A. D. Measuring the burden of neglected tropical diseases: the global burden of disease framework. PLoS Neglected Tropical Disiase, Estados Unidos, v. 1, p. e114, 2007. doi: 10.1371/journal.pntd.0000114.

MEDZHITOV, R.; JANEWAY, C. A. Innate immune induction of the adaptive immune response. Cold Spring Harbor Symposia on Quantitative Biology, Estados Unidos, v. 64, p. 429-435, 1999.

MILES, M. A.; LANHAM, S. M.; POVOA, M. Further enzymic characters of Trypanosoma cruzi in their evaluation for strain identification. Transactions of the Royal Society of Tropical Medicine and Hygiene, Inglaterra, p. 74, v. 221-237, 1980.

MONCADA, D.; KEELLER, K.; CHADEE K. Entamoeba histolytica cysteine proteinases disrupt the polymeric structure of colonic mucin an alter its protective function. Infection and Immunity, Estados Unidos, v. 71, p. 838-844, 2003. doi: 10.1128/IAI.71.2.838-844.2003.

MORAES, R. G.; Parasitologia médica. Atheneu, Brasil, v. 11, p.104-107, 1971.

NASCIMENTO, M. J. M. Mercado e Comercialização de Frutos de Açaí. Belém: CFCH/UFPA, (Relatório de Pesquisa Tomo III). Brasil, 1992.

NEIRA, I.; SILVA, F. A.; CORTEZ, M.; YOSHIDA, N. Involvement of Trypanosoma cruzi metacyclic tripomastigote surface molecule gp82 in adhesion to gastric mucin and invasion of epithelial cells Infection and Immunity, Estados Unidos, v. 71, p. 577-561, 2003.

NEUTRA, M. R.; KOZLOWSKI, P. A. Mucosal vaccines: the promise and the challenge. Nature Reviews Immunology, Inglaterra, v. 6, p. 148-158, 2006. doi:10.1038/nri1777.

O'GARRA, A. Cytokines induce the development of functionally heterogeneous T helper cell subsets. Immunity, Estados Unidos, v. 8, p. 275-283, 1998. doi: org/10.1016/S1074-7613(00)80533-6.

OLIVEIRA, M. A.; SANTIAGO, H. C.; LISBOA, C. R. Leishmania sp: comparative study with Toxoplasma gondii and Trypanosoma cruzi in their ability to initialize IL-12 and IFN-gamma synthesis. Experimental Parasitology, Estados Unidos, v. 95, p. 96-105, 2000. doi: org/10.1006/expr.2000.4523. 
OUAISSI, M. A.; CORNETTE, J.; CAPRON, A. Identification and isolation of Trypanosoma cruzi trypomastigote cell surface protein with properties expected of a fibronectin receptor. Molecular and Biochemical Parasitology, Holanda, v. 19, p. 201-211, 1986.

OZTURK, G.; AYDINLI, B.; CELEBI, F.; GURSAN, N. Gastric perforation caused by Strongyloides stercoralis: a case report. Turkish Journal of Trauma and Emergency Surgery, Turquia v. 17, p. 90-92, 2011. doi: 10.5505/tjtes.2011.51196.

PADILLA, A.; XU, D.; MARTIN, D.; TARLETON, R. Limited role for CD4+ T-cell help in the initial priming of Trypanosoma cruzi-specific CD8+ T cells. Infection and Immunity, Estados Unidos, v. 75, p. 231-235. 2007. doi: 10.1128/IAI.01245-06.

PELLEGRINO, J. Transmissão da doença de Chagas por transfusão de sangue. Primeiras comprovações sorológicas em doadores e candidatos a doadores. Revista da Sociedade Brasileira de Medicina Tropical, Brasil, v. 6, p. 297-301, 1949.

PEREZ, A. R.; MORROT, A.; BERBERT, L. R.; TERRA-GRANADO, E.; SAVINO, W. Extrathymic CD4+CD8+ lymphocytes in Chagas disease: possible relationship with an immunoendocrine imbalance. Annals of the New York Academy of Sciences, Estados Unidos, v. 62, p. 27-36, 2012. doi: 10.1111/j.1749-6632.2012.06627.x.

PEREZ, A. R.; ROGGERO, E.; NICORA, A.; PALAZZI, J.; BESEDOVSKY, H. O.; DEL REY, A.; BOTTASSO, O. A. Thymus atrophy during Trypanosoma cruzi infection is caused by an immuno-endocrine imbalance. Brain, Behavior, and Immunity, Estados Unidos, v. 21, p. 890-900, 2007. doi: 10.1016/j.bbi.2007.02.004.

PINSKY, D. J.; WALIF, A. J. I.; SZABOLCS, M.; ATHAN, E. S.; LIU, Y. YANG, Y. M.; KLINE, R. P.; OLSON, K. E.; CANNON, P. J. Nitric oxide triggers programmed cell death (apoptosis) of adult rat ventricular myocytes in culture. American Journal of Physiology, Estados Unidos, v. 277, p. 1189-1199, 1999.

PINTO, A. Y. N.; HARADA, G. S.; VALENTE, V. C. Acometimento cardíaco em pacientes com doença de Chagas aguda em microepidemia familiar, em Abaetetuba, na Amazônia Brasileira. Revista do Instituto de Medicina Tropical, Brasil, v. 34, p. 409-413, 2001.

PINTO, P. L. S.; AMATO NETO, V.; NASCIMENTO, S. A. B.; BRAZ LIMA, A. Observação sobre a viabilidade do Trypanosoma cruzi no caldo de cana. Revista do Instituto de Medicina Tropical, Brasil, v. 32, p. 325-327, 1990. 
POLLEVICK G. D.; AFFRANCHINO, J. L.; FRASH, A. C.; SANCHEZ, D. O.; The complete sequence of a shed acute-phase antigen of Trypanosoma cruzi. Molecular and Biochemical Parasitology, Holanda, v. 47, p. 247-250, 1991.

REED, S. G. Cytokine control of the macrophage parasites Leishmania and Trypanosoma cruzi. In Molecular Approaches to Parasitology, Estados Unidos, p. 443-445, 1995.

REICHE, E. M. V.; JANKEVICIUS, J. V. Avaliação de métodos alternativos para o diagnóstico laboratorial confirmatório da doença de Chagas. Revista brasileira de análises clínicas, Brasil, v. 29, p. 29-40, 1997.

REYES, J. L.; TERRAZAS, L. I.; ESPINOZA, B.; CRUZ-ROBLES, D.; SOTO, V.; RIVERA-MONTOYA, I. Macrophage migration inhibitory factor contributes to host defense against acute Trypanosoma cruzi infection. Infection and Immunity, Estados Unidos, v. 74, p. 3170-3179, 2006. doi: 10.1128/IAI.01648-05.

ROUND, J. L.; MAZMANIAN, S. K. The gut microbiota shapes intestinal immune responses during health and disease. Nature Reviews Immunology, Inglaterra, v. 9, p. 313-323, 2009. doi:10.1038/nri2515.

SANTANA, A. C.; AMIM, M. M. Cadeias Produtivas e oportunidades de negócios na Amazônia. Belém: UNAMA; FCAP., Brasil, 2002.

SANTANA, J. M.; GRELLIER, P.; SCHREVEL, J.; TEIXEIRA, A. R. A trypanosoma cruzi-secreted $80 \mathrm{kDa}$ proteinase with especificity for human collagen types I and IV. The Biochemical Journal, Inglaterra, v. 325, p. 129-137, 1997.

SCHOFIELD, C. J.; JANNIN, J.; SALVATELLA, R. The future of Chagas' disease control. Trends Parasitology, Inglaterra, v. 22, p. 583-588, 2006. doi:10.1016/j.pt.2006.09.011

SCHENKMAN S.; DIAS, C.; NUSSENZWEIG, V. Attachment of Trypanosoma cruzi trypomastigotes to receptors at restricted cell surface domains. Experimental Parasitology, Estados Unidos, v. 72, p. 76-86, 1991.

SCHOFIELD, C. J. Biosystematics of the Triatominae. Service MW, ed. Biosystematics of Haematophagous Insects. Oxford: Clarendon Press, Inglaterra, v. 37, p. 285-312, 1988.

SCHNAPP, A. R.; EICKHOFF, C. S.; SIZEMORE, D.; CURTISS III, R.; HOFT, D. F. Cruzipain induces both mucosal and systemic protection against Trypanosoma cruzi in mice. Infection and Immunity, Estados Unidos, v. 70, p. 5065-5074, 2000. doi: 10.1128/IAI.70.9.5065-5074.2002. 
SHIKANAI-YASSUDA, M. A.; LOPES, M. H.; TOLEZANO, J. E.; UMEZAWA, E.; AMATO NETO, V.; BERRETO, A. C. P.; HIGAKI, Y.; MOREIRA, A. A. B.; FUNAYAMA, G.; BARONE, A. A.; DUARTE, A.; ODONE, V.; CERRI, G. C.; SATO, M.; POSI, D.; SHIMORA, M. Doença de chagas aguda: vias de transmissão, aspectos clínicos e respostas à terapêutica específica em casos diagnosticados em um centro urbano. Revista do Instituto de Medicina Tropical, Brasil, v. 35, p. 1627, 1990.

SILVA, J. S.; VESPA, G. N.; CARDOSO, M. A.; ALIBERTI, J. C.; CUNHA, F. Q. Tumor necrosis factor alpha mediates resistance to Trypanosoma cruzi infection in mice by inducing nitric oxide production in infected gamma interferon-activated macrophages. Infection and Immunity, Estados Unidos, v. 63, p. 4862-4867, 1995.

SILVA, N. N.; CLAUSELL, D. T.; NÓBILIS, H.; DE MELLO, A. L.; OSSANAI, J.; RAPONE, T. Epidemic outbreak of Chagas disease probably due to oral contamination. Revista do Instituto de Medicina Tropical, Brasil, v. 10, p. 265-76, 1968.

SILVA, L. H. P.; NUSSENZWEIG, V. Sobre uma cepa de Trypanosoma cruzi altamente virulenta para o camundongo branco. Folha Clínica et Biologica de São Paulo, Brasil, v. 20, p. 191-201,1953.

SCHMAUSSER, B.; ANDRULIS, M.; ENDRICH, S.; LEE, S. K.; JOSENHANS, C.; MULLER-HERMELINK, H. K.; ECK, M. Expression and subcellular distribution of tolllike receptors TLR4, TLR5 and TLR9 on the gastric epithelium in Helicobacter pylori infection. Clinical and Experimental Immunology, Inglaterra, v. 136, p. 521-526, 2004. doi: 10.1111/j.1365-2249.2004.02464.x.

SOARES, V. A.; DIAS, J. C. P.; MARSDEN, P. D. Sobrevivência do Trypanosoma cruzi em caldo de cana: resultados preliminares. Revista do Instituto de Medicina Tropical de São Paulo, Brasil, v. 20, p. 38-41, 1987.

SOGAYAR, R.; KIPNIS, T. L.; CURI, P. R. Acritical evaluation of the expression of parasitemia in experimental Chagas' disease. Revista do Instituto de Medicina Tropical, Brasil, v. 35, p. 395-398, 1993. doi:10.1590/S0036-46651993000500002.

SOUTO, R. P.; ZINGALES, B. Sensitive detection and classification of Trypanosoma cruzi by amplification of a ribosomal RNA sequences. Molecular and Biochemical Parasitology, Holanda, v. 62, p. 45-52, 1993.

SOUZA, M. M.; ANDRADE, S. G.; BARBOSA, J. R. A. A.; SANTOS, T. T. M.; ALVES, V. A. F.; ANDRADE, Z. A. Trypanosoma cruzi strains and autonomic nervous system pathology in experimental Chagas disease. Memórias do Instituto Oswaldo Cruz, Brasil, v. 91, p. 217-224, 1996. 
TALIAFERRO, W. H.; PIZZI, T. Connective tissue reactions in normal and immunized mice to a reticulotropic strain of Trypanosoma cruzi. Journal of Infectious Diseases, Estados Unidos, v. 96, p. 199-226, 1955.

TARLETON, R. L.; SUN, J.; ZHANG, L.; POSTAN, M. Depletion of T-cell subpopulationsresults in exacerbation of myocarditis and parasitism in experimental Chagas'disease. Infection and Immunity, Estados Unidos, v. 62, p. 1820-1829, 1994.

TARLETON, R. L. Tumour necrosis factor (cachectin) production during experimental Chagas' disease. Clinical \& Experimental Immunology, Inglaterra, v. 73, p. 186190, 1988.

TERENZI, F.; DIAZ-GUERRA, M. J. M.; CASADO, M.; HORTELANO, S.; LEONI, S.; BOSCÁ, L. Bacterial Lipopetides Induce Nitric Oxide Syntetase and promote apoptosis throught Nitric Oxide - Independent pathways in rats macrophages. Journal of Biological Chemistry, United States, v. 270, p. 6017-6021, 1995.

TRUYENS, C.; TORRICO, F.; LUCAS, R.; BAETSELIER, P.; BUURMAN, W. A.; CARLIER, Y. The endogenous balance of soluble tumor necrosis factor receptors and tumor necrosis factor modulates cachexia and mortality in mice acutely infected with Trypanosoma cruzi. Infection and Immunity, Estados Unidos, v. 67, p. 55795586. 1999.

VALENTE, S. A.; VALENTE, V. C.; PINTO, A. Y. Epidemiologia e transmissão oral da doença de Chagas na Amazônia brasileira. In: Informe de la consulta técnica em pidemiologia, prevencion y manejo de la transmision de la enfermidad de chagas como enfermidad transmitida por alimentos (ETA). Washington: Organizacion Panamericana de La Salud/Organizacion Mundial de La Salud, p. 21-6, 2006.

VALENTE, S. A. S.; PIMENTEL, O. S.; VALENTE, V. C. Microepidemia familiar de doença de Chagas em Santarém. Primeiro registro no oeste do Pará. Revista do Instituto de Medicina Tropical de São Paulo, Brasil, v. 34, p.19-20, 2001.

WORLD HEALTH ORGANIZATION. Control of the Chagas disease. Who technical report series. França, v. 905, 2002.

WANG, A. Y.; PEURA, D. A. The prevalence and incidence of Helicobacter pyloriassociated peptic ulcer disease and upper gastrointestinal bleeding throughout the world. Gastrointestinal Endoscopy Clinics of North America, Estados Unidos, v. 21, p. 613-635, 2011. doi: 10.1016/j.giec.2011.07.011. 
WORLD HEALTH ORGANIZATION. Report of the steering committees research activities of the scientific working group (SWG) on Chagas disease. Memórias do Instituto Oswaldo Cruz, Brasil, v. 81, p. 181-244, 1986.

YAMAMOTO, M.; VANCOTT, J. L.; OKAHASHI, N.; MARINARO, M.; KIYONO, H.; FUJIHASHI, K.; JACKSON, R. J.; CHATFIELD, S. N.; BLUETHMANN, H.; MCGHEE, J. R. The role of Th1 and Th2 cells for mucosal IgA responses. Annals of the New York Academy of Sciences, Estados Unidos, v. 778, p. 64-71, 1996. doi: 10.1111/j.1749-6632.1996.tb21115.x.

YOSHIDA, N. Molecular basis of mammalian cell invasion of Trypanosoma cruzi. Anais da Academia Brasileira de Ciências, v. 78, p. 87-111, 2006.

YOSHIDA, N. Molecular mechanisms of Trypanosoma cruzi infection by oral route. Memórias do Instituto Oswaldo Cruz, Brasil, v. 104, p. 101-107, 2009.

YOSHIDA, N.; FAVORETO-JR, S.; FERREIRA, A. T.; MANQUE, P. M. Signal transduction induced in Trypanosoma cruzi metacyclic tripomastigotes during the invasion of mammalian cells. Brazilian Journal of Medical and Biological Research, Brasil, v. 33, p. 269-278, 2000.

ZHANG, L.; TARLETON, R. L. Parasite persistence correlates with disease severity and localization in chronic Chagas' disease. Journal of Infectious Diseases, Estados Unidos, v. 180, p. 480-486, 1999. doi: 10.1086/314889. 